\title{
Water mass transformation in the North Atlantic over 1985-2002 simulated in an eddy-permitting model
}

\author{
R. Marsh, S. A. Josey, A. J. G. Nurser, B. A. de Cuevas, and A. C. Coward \\ National Oceanography Centre, Southampton, UK \\ Received: 11 February 2005 - Published in Ocean Science Discussions: 11 April 2005 \\ Revised: 19 August 2005 - Accepted: 26 September 2005 - Published: 25 October 2005
}

\begin{abstract}
Water mass transformation in the North Atlantic is examined in an eddy-permitting simulation with the OCCAM ocean general circulation model, forced by realistic surface fluxes over the period 1985-2002. Three Atlantic regions are considered - the subtropics, mid-latitudes, the northeast Atlantic - along with the Labrador Sea. The oceanic boundaries of each region coincide with hydrographic sections occupied in recent years. These regions broadly represent the formation sites of Eighteen Degree Water (EDW), Subtropical Mode Water (STMW), Subpolar Mode Water (SPMW) and Labrador Sea Water (LSW). Water mass budgets are obtained for each region and year. Terms in the budget comprise surface-forced transformation rates, boundary exchanges and unsteadiness. Transformation rates due to "total mixing" are obtained as the difference between net and surface transformation rates. Transports at the boundaries are evaluated alongside recent hydrographic section datasets, while surface-driven and mixing-driven transformation rates are compared with estimates based on air-sea flux datasets and inverse analysis of hydrographic data. In general OCCAM compares well with the observations, although two particular discrepancies are identified: deep overflows at high latitudes too light by around $0.2 \mathrm{~kg} \mathrm{~m}^{-3}$ and spurious heat gain of up to $100 \mathrm{Wm}^{-2}$ east of the Grand Banks. Over 1985-2002, there is considerable variability on a range of timescales, in the annual surface-driven and mixing-driven formation rates of all four water masses. In the case of EDW and STMW, surface-driven and mixing-driven formation rates largely cancel. This is not so for SPMW and LSW, leading to regional net formation rates of up to $17 \mathrm{~Sv}$ and $15 \mathrm{~Sv}$, respectively. In particular, OCCAM successfully simulates the strong LSW formation event of 1989-1994.
\end{abstract}

Correspondence to: R. Marsh

(rma@noc.soton.ac.uk)

\section{Introduction}

Progressive surface density gain along upper circulation pathways in the North Atlantic drives water mass transformation, leading to the formation of water masses in distinct ranges of potential density $\left(\sigma_{0}\right)$ and geographical extent: Eighteen Degree Water (EDW), $26.4<\sigma_{0}<26.6 \mathrm{~kg} \mathrm{~m}^{-3}$ in the Sargasso Sea; Subtropical Mode Water (STMW), $26.6<\sigma_{0}<27.2 \mathrm{~kg} \mathrm{~m}^{-3}$ across the northern subtropical gyre [although identified seperately in this study, EDW could equally be considered as the lightest variety of STMW]; Subpolar Mode Water (SPMW), $27.2<\sigma_{0}<27.7 \mathrm{~kg} \mathrm{~m}^{-3}$ in the eastern subpolar gyre; Labrador Sea Water (LSW), $27.7<\sigma_{0}<28.0 \mathrm{~kg} \mathrm{~m}^{-3}$ in the western subpolar gyre. Increases in surface density are principally due to winter cooling (McCartney and Talley, 1984), although the formation mechanism varies with progression northwards. In the subtropical gyre, EDW and STMW are formed at the end of winter through subduction into the permanent thermocline across the base of the winter mixed layer which reaches depths of up to $300 \mathrm{~m}$ (Marshall et al., 1993). In the subpolar gyre, SPMW is principally formed through winter convection to around $500 \mathrm{~m}$ (Pérez-Brunius et al., 2004) while in the Labrador Sea, LSW is formed during deep convective mixing up to $1500 \mathrm{~m}$ (Pickart et al., 2002). Following surface formation, water mass consumption is driven by diapycnal mixing (Tziperman, 1986).

Regionally, the net rate at which a water mass is formed can be estimated from tracers (Rhein et al., 2002) or by inversions of measured transports across hydrographic sections (Ganachaud, 2003; Lumpkin and Speer, 2003), although such estimates are compromised by large uncertainties. Ocean General Circulation Models (OGCMs) have also been used to exactly determine formation rates (Nurser et al., 1999), although the problem of water mass unsteadiness in models is a recognised drawback (Nurser and Marsh, 1998).

(C) 2005 Author(s). This work is licensed under a Creative Commons License. 
Interannual-to-decadal variability in water mass formation rates is suggested by evidence for changes in the volume and properties of STMW (Alfutis and Cornillon, 2001; Kwon and Riser, 2004), SPMW (Thierry et al., 2004) and LSW (Dickson et al., 1996). Such variability is most directly a consequence of changes in local surface fluxes, which have been associated with leading modes of atmospheric variability such as the North Atlantic Oscillation (NAO). Secular trends in water mass formation rates may also be associated with climate change (Dickson et al., 2003).

The role of diapycnal mixing in water mass variability is much less clear. Regionally-integrated diapycnal fluxes due to mixing have been evaluated in OGCMs under climatological forcing and boundary conditions (e.g. Nurser et al., 1999) and most recently in coupled climate models (e.g. Haines and Old, 2005). Mixing may be especially strong in the vicinity of fronts and eddies. In the low resolution OGCMs previously used to diagnose water mass transformation rates (e.g. Nurser et al., 1999), fronts are too broad and eddies are parameterized. Experiments with an eddy-resolving ocean model configured in an idealized basin showed that eddies enhance subduction rates (hence STMW formation) by a factor of $\sim 2$ (Hazeleger and Drijfhout, 2000), and studies of the subduction process are now being carried out with eddyresolving OGCMs configured in realistic geometry (e.g. Valdivieso da Costa et al., 2005).

Combining advances in both resolution and forcing, we diagnose water mass transformation in an eddy-permitting OGCM forced by realistic surface fluxes over 1985-2002. We validate the transport and transformation of water masses in the model by comparison with selected observations, and by considering simulated variability alongside observational evidence for recent changes in the North Atlantic. By doing this we aim to answer the following questions:

1. What role does mixing play in the net formation of principal water masses in the North Atlantic according to an eddy-permitting model?

2. To what extent are the model results for the role of mixing consistent with findings from inverse studies?

3. How variable are surface-driven, mixing-driven and net water mass formation rates in the North Atlantic?

The paper is arranged as follows. The model configuration, forcing and spin-up are described in Sect. 2. Diagnostic procedures are outlined in Sect. 3. Results are presented in Sect. 4. In Sect. 5 the results are discussed in comparison with other model studies and observations.

\section{The model}

\subsection{Basic configuration}

The data used in this analysis is output from the latest run of the Ocean Circulation and Climate Advanced Model (OC-
CAM) global ocean model. OCCAM is based on the BryanCox-Semtner general ocean circulation model (Bryan, 1969; Semtner, 1974; Cox, 1984). The version used here combines $1 / 4^{\circ} \times 1 / 4^{\circ}$ horizontal resolution with high vertical resolution - 66 levels with 14 in the top $100 \mathrm{~m}$. While the horizontal resolution is eddy permitting across most of the domain, shortening of the Rossby radius towards high latitudes restricts eddy resolution poleward of about $70^{\circ} \mathrm{N}$. Improved physics packages have been introduced as well as a sophisticated sea ice model with elastic-viscous-plastic (EVP) dynamics (Hunke and Dukowicz, 1997) and thermodynamics based on that of Semtner (1976). The version of OCCAM used here features the KPP mixed layer of Large et al. (1994) and the isoneutral mixing scheme of Griffies et al. (1998). The eddy-stirring process of Gent and McWilliams (1990) is included as a skew flux (Griffies, 1998). Where isopycnal slopes become large, exponential tapering scales isoneutral diffusivities to zero as the slope increases (Danabasoglu and McWilliams, 1995). As use of the KPP mixed layer scheme can lead to large isopycnal slopes near the ocean surface, additional tapering reduces isopycnal mixing in the vicinity (as in Large et al., 1997). Model parameters of relevance to this study are listed in Table 1.

\subsection{Surface forcing: scheme and data}

Several features of the new model allow us to capture the spatial and temporal variability of the upper ocean. Key to this is a comprehensive set of high frequency (6-hourly) atmospheric fields together with a realistic bulk formulation of atmospheric forcing. Input fields of wind speed, air temperature, specific humidity, sea level pressure, cloudiness, precipitation and short wave radiation are used in combination with the model top level potential temperature to compute the wind stress, heat and freshwater forcing to be applied at each time step. The input data for the period 1985-2002 were supplied by NCAR, and are described in Large et al. (1997). Sixhourly zonal and meridional $10 \mathrm{~m}$ wind components, $2 \mathrm{~m}$ air temperature and specific humidity are from the NCEP reanalysis (Kalnay et al., 1996). The air temperature and specific humidity are shifted to $10 \mathrm{~m}$. Monthly cloud fraction data are from the ISCCP C1 dataset (Rossow and Schiffer, 1991) for the period 1985 to June 1991 and filled in with climatology for succeeding years. Monthly solar radiation is based on the daily ISCCP data (Bishop and Rossow, 1991) for the period 1984 to June 1991 and filled in with climatology for succeeding years. Monthly precipitation is based on the monthly Microwave Sounding Unit (MSU) (Spencer, 1993) satellite data products. Where available, the Xie and Arkin (1997) observational precipitation data has been blended with the MSU climatology, but for later years climatology has been used. Upgraded model physics and the use of realistic, balanced surface forcing have led to improved simulation of the Atlantic thermohaline circulation compared to an earlier OCCAM simulation in which sea surface temperatures 
Table 1. OCCAM viscosities and tracer mixing parameters. The schemes are abbreviated as follows: KPP - the Large et al. (1997) mixed layer scheme; G98 - the Griffies et al. (1998) isopycnal mixing scheme; DM97 - the Danabasoglu and McWilliams (1997) tapering of isopycnal diffusivity; GM90 - the Gent and McWilliams (1998) eddy parameterisation.

\begin{tabular}{lcc}
\hline Parameter & Scheme & Value \\
\hline Viscosity due to shear instability & KPP & $50 \mathrm{~cm}^{2} \mathrm{~s}^{-1}$ \\
Diffusivity due to shear instability & KPP & $50 \mathrm{~cm}^{2} \mathrm{~s}^{-1}$ \\
Vertical viscosity coefficient limit & KPP & $1000 \mathrm{~cm}^{2} \mathrm{~s}^{-1}$ \\
Vertical diffusion coefficient limit & KPP & $1000 \mathrm{~cm}^{2} \mathrm{~s}^{-1}$ \\
Background vertical diffusion coefficient & KPP & $0.5 \mathrm{~cm}^{2} \mathrm{~s}^{-1}$ \\
Background viscosity coefficient & KPP & $10 \mathrm{~cm}^{2} \mathrm{~s}^{-1}$ \\
Along isoneutral diffusion coefficient & G98 & $5 \times 10^{5} \mathrm{~cm}^{2} \mathrm{~s}^{-1}$ \\
Maximum isoneutral slope & G98 & 0.01 \\
Transition for scaling isoneutral diffusivities & DM97 & 0.004 \\
Half-width scaling for diffusivity & DM97 & 0.001 \\
Skew flux diffusion coefficient & GM90 & $5 \times 10^{5} \mathrm{~cm}^{2} \mathrm{~s}^{-1}$ \\
\hline
\end{tabular}

and salinities were restored to monthly climatological values (Hirschi et al., 2003).

\subsection{Initialisation and spin-up}

The initial tracer fields (potential temperature and salinity) were interpolated from the WOCE SAC climatology (Gouretski and Jancke 1998) for most of the World's oceans together with tracer distributions for the Arctic from the merger of World Ocean Atlas data and the Arctic Ocean Atlas data (Steele et al., 2001). The sea ice model was initialised with $15 \mathrm{~cm}$ of snow and $150 \mathrm{~cm}$ of sea-ice south of $65.5^{\circ} \mathrm{S}$ around Antarctica and $10 \mathrm{~cm}$ of sea-ice north of $70^{\circ} \mathrm{N}$ in the Arctic. Fractional cover was assumed to be 0.99 in each affected grid cell. The model was first integrated from its initial state for four model-years using atmospheric fields from 1985 to 1988 . The final state from this run was then used to initialise an 18-year integration using atmospheric fields from 1985 to 2002 . Running totals of the model variables and forcing fields were accumulated during the model run and output at the end of each month, and subsequently used to calculate the monthly mean fields for this analysis. See Coward and de Cuevas (2005) for full details of this OCCAM simulation.

\section{Diagnostics}

The combined effects of surface buoyancy forcing and mixing are evident in analyses of upper ocean heat budgets (e.g. Niiler and Stevenson, 1982). Walin (1982) introduced a conceptual framework for water mass transformation, subsequently applied by Speer and Tziperman (1992) and Garrett et al. (1995) in the context of a buoyancy budget. Here we diagnose water mass transformation rates partitioned according to potential density $\left(\sigma_{0}\right)$. In the North Atlantic, water masses can be unambiguously defined according to $\sigma_{0}$, although this approach is problematic elsewhere in the World Ocean, notably in the Southern Ocean. Using the index $k$ to denote progressively higher $\sigma_{0}$, we can relate a rate of change in the regional volume, $V\left(\sigma_{k-1}, \sigma_{k}\right)$, of a layer bounded by density surfaces $\sigma_{k-1}$ and $\sigma_{k}$, and open boundaries, to surface fluxes, diapycnal mixing and net advection across the boundaries:

$$
\begin{aligned}
& \partial_{t} V\left(\sigma_{k}, \sigma_{k-1}\right)= \\
& \left(\psi_{\text {net }}\left(\sigma_{k}\right)-\psi_{\text {net }}\left(\sigma_{k-1}\right)\right)-\left(G\left(\sigma_{k}\right)-G\left(\sigma_{k-1}\right)\right),
\end{aligned}
$$

where $\psi_{\text {net }}\left(\sigma_{k}\right)$ is a net density-partitioned overturning streamfunction, integrated down from the surface (taking all open boundaries into account), and $G\left(\sigma_{k}\right)$ is the net diapycnal volume transport (positive towards higher density) within the region, across the surface defined by $G\left(\sigma_{k}\right)$. Averaging over one or more annual cycles, the left hand side of Eqn. (1) gives a measure of regional water mass unsteadiness. The transport $G\left(\sigma_{k}\right)$ is a net "water mass transformation rate", due to a combination of surface and interior diapycnal volume fluxes:

$G\left(\sigma_{k}\right)=G_{\text {surf }}\left(\sigma_{k}\right)+G_{\text {mix }}\left(\sigma_{k}\right)$,

where $G_{\text {surf }}\left(\sigma_{k}\right)$ and $G_{\text {mix }}\left(\sigma_{k}\right)$ are the transformation rates due, respectively, to surface buoyancy fluxes and "total" mixing (defined below). In OCCAM, we compute $G_{\text {surf }}\left(\sigma_{k}\right)$ from monthly datasets, on the model $(i, j)$ grid, as:

$$
\begin{aligned}
& G_{\text {surf }}\left(\sigma_{k}\right)= \\
& \frac{1}{12} \sum_{m=1}^{12} \frac{1}{\left(\sigma_{k}-\sigma_{k-1}\right)} \sum_{i, j}\left[f_{i, j, m} \Delta A_{i, j} \Pi\left(\sigma_{k}, \overline{\sigma_{i, j, \text { surf }}}\right)\right]
\end{aligned}
$$

obtained by annually averaging $f_{i, j, m}$, the monthly-mean surface flux of density (units $\mathrm{kg} \mathrm{m}^{-3} \mathrm{~s}^{-1}$ ) due to net surface heat and freshwater fluxes, integrated over the area bound by the outcropping of isopycnals $\sigma_{k}$ and $\sigma_{k-1}$ (where $\Delta A_{i, j}$ is 


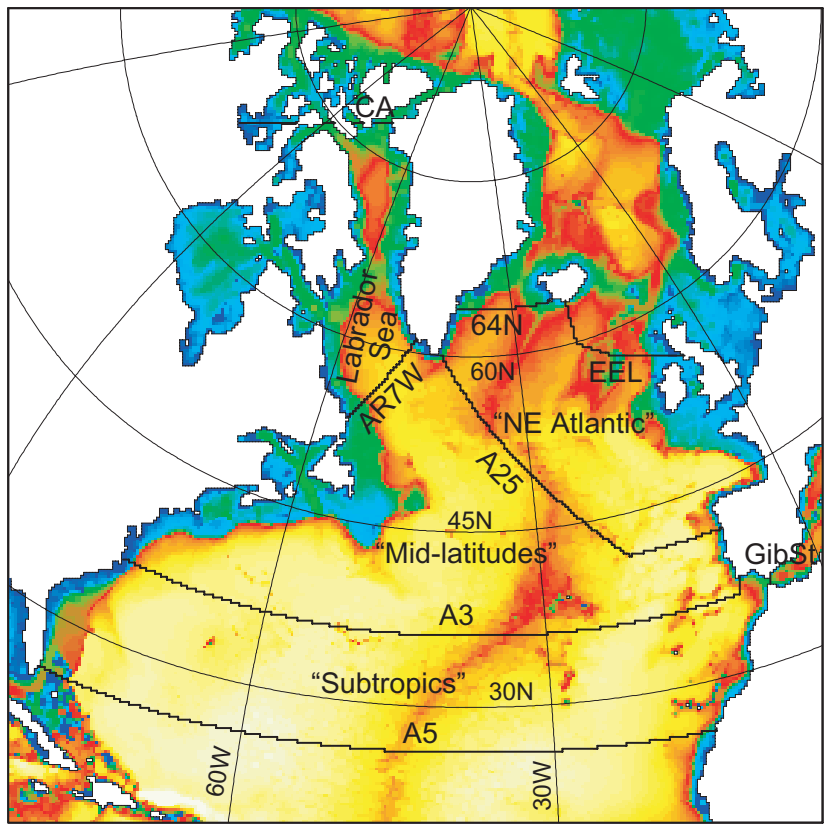

Fig. 1. The extra-tropical North Atlantic of OCCAM, showing model bathymetry and the major model sections (indicated in bold), which follow the sides of gridcells to exactly capture model transports. The four enclosed regions are labelled. OCCAM uses a rotated grid to represent the North Atlantic and the Arctic. For orientation, meridians are shown at $30^{\circ}$ intervals, and lines of latitude at $15^{\circ}$ intervals.

gridbox area, $\Pi\left(\sigma_{k}, \overline{\sigma_{i, j, \text { surf }}}\right)$ is a sampling function which takes the value 1 if $\sigma_{k-1} \leq \overline{\sigma_{i, j, \text { surf }}} \leq \sigma_{k}$, otherwise the value 0 , given $\overline{\sigma_{i, j, \text { surf }}}$, the monthly-mean surface density). The second term of the right hand side of Eq. (2) can be further decomposed into contributions from different diapycnal mixing processes (Nurser et al., 1999) and other processes which lead to density gain (McDougall, 1991), as well as the spurious diapycnal mixing which arises in numerical models (Griffies et al., 2000):

$G_{\text {mix }}=G_{\text {lat }}+G_{\text {ent }}+G_{\text {thermo }}+G_{\text {cab }}+G_{\text {spurious }}$

where $G_{\text {lat }}$ is associated with lateral mixing across outcropping isopycnals in the mixed layer, $G_{\text {ent }}$ is associated with entrainment at the base of the mixed layer, $G_{\text {thermo }}$ is the diffusive density flux in the main thermocline (including vigorous turbulent mixing in the bottom boundary layer), $G_{\text {cab }}$ is the cabbeling (density gain) due to isopycnal mixing (most notable in frontal regions where there are strong temperarture and salinity gradients on isopycnals), and $G_{\text {spurious }}$ is the spurious diapycnal mixing which arises in $z$-coordinate models such as OCCAM.

We obtain $\psi_{\text {net }}\left(\sigma_{k}\right)$ (Eq. 1) for a selection of sections through the model grid which coincide as closely as possible with hydrographic lines occupied during WOCE and planned under the auspices of CLIVAR. The sections (see Fig. 1) are as follows:
1. A5, along $26^{\circ} \mathrm{N}$.

2. A3, along $36^{\circ} \mathrm{N}$ except in the east where the section terminates at the Spanish coast.

3. A25, at $41.5^{\circ} \mathrm{N}$ from the Spanish coast to $20^{\circ} \mathrm{W}$, thereafter towards Cape Farewell, Greenland.

4. AR7W, from southwest Greenland to the Labrador Shelf.

5. The Extended Ellett Line (EEL), from the Scottish Hebrides via Rockall to South Iceland along $20^{\circ} \mathrm{W}$, continued from West Iceland to Greenland along $64^{\circ} \mathrm{N}$ ("EEL-64N").

Sections $2-5$ coincide as close as possible with actual occupations. For convenience, the model "A5" section follows $26^{\circ} \mathrm{N}$, rather than following exactly the actual section, which deviates between $24^{\circ} \mathrm{N}$ and $26.5^{\circ} \mathrm{N}$. To fully enclose regions, we also include short sections across the Straits of Gibraltar (GibSt) and the Canadian Archipelago (CA). The sections are indicated on Fig. 1. We thus identify four regions enclosed by sections as follows:

1. A5-A3-GibSt: "Subtropics" Box.

2. A3-AR7W-A25: "Mid-latitudes" Box.

3. A25-EEL-64N: "NE Atlantic" Box.

4. AR7W-CA: "Labrador Sea" Box.

For each region, boundary streamfunctions are partitioned according to density $-\psi_{\mathrm{A} 5}\left(\sigma_{k}\right), \psi_{\mathrm{A} 3}\left(\sigma_{k}\right), \psi_{\mathrm{GibSt}}\left(\sigma_{k}\right)$, $\psi_{\mathrm{A} 25}\left(\sigma_{k}\right), \psi_{\mathrm{AR} 7 \mathrm{~W}}\left(\sigma_{k}\right), \psi_{\mathrm{EEL}}\left(\sigma_{k}\right), \psi_{64 \mathrm{~N}}\left(\sigma_{k}\right), \psi_{\mathrm{CA}}\left(\sigma_{k}\right)-$ and combined to determine the net imports:

$$
\begin{aligned}
& \psi_{\text {net }}^{\text {subtrop }}\left(\sigma_{k}\right)=\psi_{\mathrm{A} 5}\left(\sigma_{k}\right)-\left(\psi_{\mathrm{A} 3}\left(\sigma_{k}\right)+\psi_{\mathrm{GibSt}}\left(\sigma_{k}\right)\right) \\
& \psi_{\text {net }}^{\text {midlat }}\left(\sigma_{k}\right)=\psi_{\mathrm{A} 3}\left(\sigma_{k}\right)-\left(\psi_{\mathrm{A} 25}\left(\sigma_{k}\right)+\psi_{\mathrm{AR} 7 \mathrm{~W}}\left(\sigma_{k}\right)\right) \\
& \psi_{\text {net }}^{\mathrm{NEAtl}}\left(\sigma_{k}\right)=\psi_{\mathrm{A} 25}\left(\sigma_{k}\right)-\left(\psi_{\mathrm{EEL}}\left(\sigma_{k}\right)+\psi_{64 \mathrm{~N}}\left(\sigma_{k}\right)\right) \\
& \psi_{\text {net }}^{\text {LabSea }}\left(\sigma_{k}\right)=\psi_{\mathrm{AR} 7 \mathrm{~W}}\left(\sigma_{k}\right)-\psi_{\mathrm{CA}}\left(\sigma_{k}\right)
\end{aligned}
$$

For each region we also diagnose $\partial_{t} V\left(\sigma_{k}, \sigma_{k-1}\right)$, and hence $G\left(\sigma_{k}\right)$ (see Eq. 1), and $G_{\text {surf }}\left(\sigma_{k}\right)$. We then follow the common practice of inferring $G_{\text {mix }}$ as a residual term (Speer et al., 1997; Marshall et al., 1999). Formation rates are defined in the density range $\sigma_{k-1}$ to $\sigma_{k}$ as:

$$
\begin{aligned}
& M_{\text {surf }}\left(\sigma_{k-1}, \sigma_{k}\right)=-\left(G_{\text {surf }}\left(\sigma_{k}\right)-G_{\text {surf }}\left(\sigma_{k}-1\right)\right) \\
& M_{\text {mix }}\left(\sigma_{k-1}, \sigma_{k}\right)=-\left(G_{\text {mix }}\left(\sigma_{k}\right)-G_{\text {mix }}\left(\sigma_{k}-1\right)\right) \\
& M_{\text {net }}\left(\sigma_{k-1}, \sigma_{k}\right)=-\left(G\left(\sigma_{k}\right)-G\left(\sigma_{k}-1\right)\right)
\end{aligned}
$$

where $M_{\text {surf }}\left(\sigma_{k-1}, \sigma_{k}\right)$ is the surface formation rate due airsea fluxes of heat and freshwater, $M_{\text {mix }}\left(\sigma_{k-1}, \sigma_{k}\right)$ is the formation rate due to all mixing, and $M_{\text {net }}\left(\sigma_{k-1}, \sigma_{k}\right)$ is the net formation rate. 
Table 2. Total transports (Sv) across OCCAM sections. Positive values indicate northward transports across the zonal and quasizonal sections, and eastward transports across GibSt. "Import" and "Export" refer to total northward/eastward and southward/westward transports, respectively.

\begin{tabular}{cccc}
\hline Section & Import & Export & Net \\
\hline A5 & 26.01 & -26.85 & -0.83 \\
A3 & 24.10 & -25.18 & -1.08 \\
GibSt & 1.17 & -1.12 & 0.05 \\
A25 & 20.10 & -19.61 & 0.49 \\
AR7W & 13.52 & -14.97 & -1.45 \\
EEL-64N & 15.29 & -14.90 & 0.39 \\
CA & 0.05 & -1.43 & -1.38 \\
\hline
\end{tabular}

Table 3. Total transports (Sv) across observed sections (where available).

\begin{tabular}{cccc}
\hline Section & Import & Export & Net \\
\hline A5 & 31.03 & -31.03 & 0.00 \\
GibSt & $0.78 \pm 0.47$ & $-0.67 \pm 0.26$ & - \\
A25 & 23.74 & -24.14 & -0.40 \\
CA & - & - & -0.7 to -2.5 \\
\hline
\end{tabular}

\section{Results}

The results are presented in four stages, progressing as follows. First we present and discuss property-binned transports across the sections, and evaluate the model using relevant observations. We then use the model results to obtain net water mass transformation rates, accounting for unsteadiness. Next, we compute surface transformation rates in OCCAM, and compare these with estimates computed with the two versions of the SOC flux dataset (Josey et al., 1999; Grist and Josey, 2003) which are described in more detail later. We then examine the difference between net and surface transformation rates, and attribute this to the total effect of mixing. Finally, formation rates are defined for each water mass, due to surface fluxes and mixing, and in net terms.

\subsection{Period-mean transports across sections}

Figure 2 shows 1985-2002 mean transports across each section, partitioned according to potential temperature $(\theta)$ and salinity (S). For direct comparison with two of the sections, Fig. 3 shows the transports estimated from recent occupations of A5 (Lavín et al., 2003) and A25 (Álvarez et al., 2002). Transports and properties on the other sections are discussed in the context of published observations. Tables 2 and 3 list the corresponding imports, exports, and net transports, for each section (observations where available). (a) A5

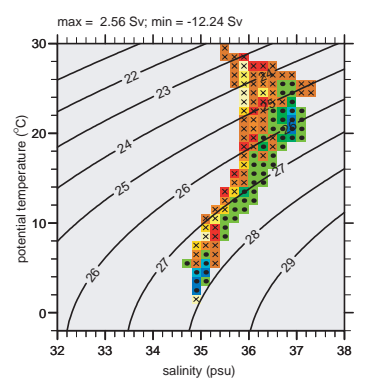

(b) $\mathrm{A} 3$

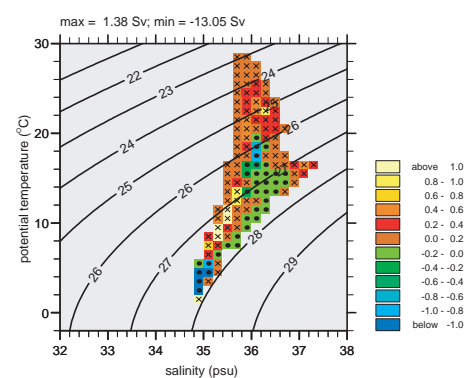

(c) GibSt

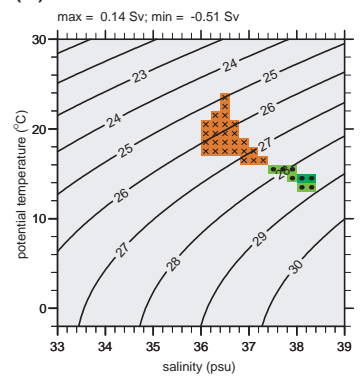

(d) A25

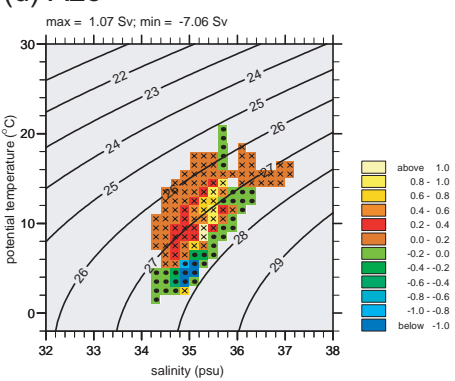

(e) AR7W

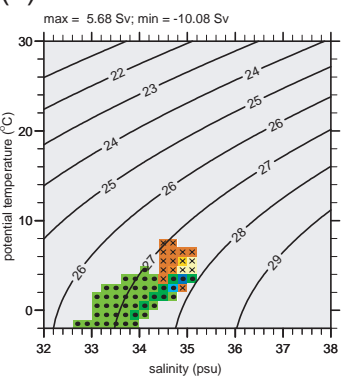

(f) $\mathrm{EEL}+64 \mathrm{~N}$

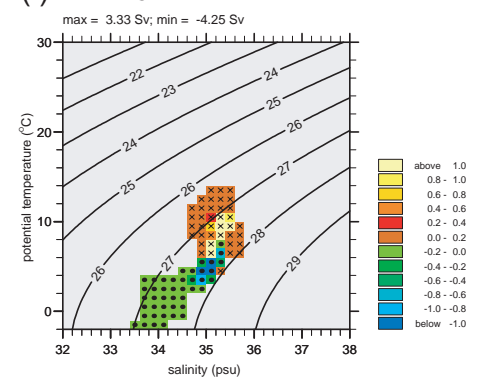

Fig. 2. Period-mean transports (units Sv, positive for northward flow) across each section partitioned in temperature and salinity: (a) A5; (b) A3; (c) GibSt; (d) A25; (e) AR7W; (f) EEL-64N. The contours indicate $\sigma_{0}(\theta, \mathrm{S})$. The salinity range in (c) is shifted +1 $\mathrm{psu}$, in order to accommodate the high salinity MW. Transports in the range -0.01 to $0.01 \mathrm{~Sv}$ are grey-shaded. For clarification of flow direction, poleward flows (and flow into Mediterrenean) are indicated by cross hairs while equatorward flows (and flow out of the Mediterrenean) are indicated by dots.

Model transport across A5 (Fig. 2a) features a northward "warm core" of $\sim 23 \mathrm{~Sv}$ in the temperature range $22-28^{\circ} \mathrm{C}$ and the salinity range $35.8-36.0 \mathrm{psu}$, corresponding to the Florida Current. Across the broader temperature range 8$26^{\circ} \mathrm{C}$ southward transports, amounting to $\sim 6 \mathrm{~Sv}$, are fresher (than northward transports) by about 1 psu, due to the effects of net evaporation north of A5. The export of North Atlantic Deep Water (NADW) comprises total southward transport of $\sim 17 \mathrm{~Sv}$ at $34.8-35.2 \mathrm{psu}$ and $2-6^{\circ} \mathrm{C}$. Antarctic Bottom Water $(\mathrm{AABW})$ provides the northward flux of $\sim 3 \mathrm{~Sv}$ at $34.8-$ $35.0 \mathrm{psu}$ and $1-2^{\circ} \mathrm{C}$. Much of the observed northward and southward-recirculating transport at A5 (Fig. 3a) is at higher salinity, by $\sim 0.2 \mathrm{psu}$. It is not clear why the equivalent model 
(a) A5

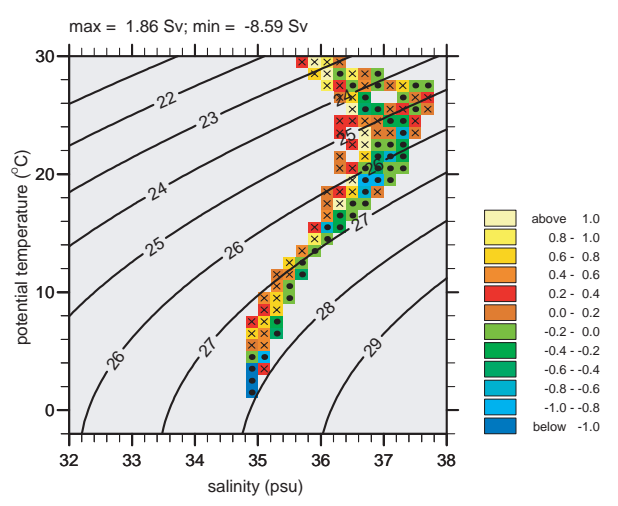

(b) A25

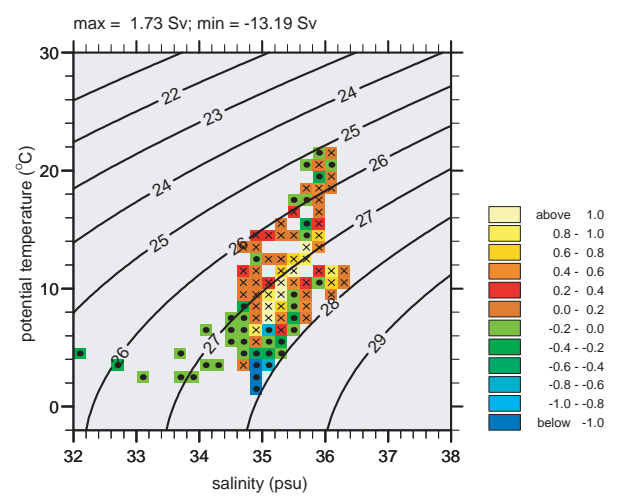

Fig. 3. As Fig. 2, based on estimates at: (a) A5 (June 1992); (b) A25 (August 1997).

transports are fresher than the observations, although there are several possible causes. As the 1992 occupation of A5 took place in June, the discrepancy may be partly due to seasonal bias. Near-surface transports (of lighter waters) may be sensitive to differences between the climatological annualmean winds used to compute Ekman transport (for the observations) and the reanalysed (6-hourly) winds applied in the model. The evaporation and precipitation rates used in OCCAM may also introduce regional salinity biases. In addition to the salinity offset, observed southward fluxes of NADW are located at lower temperature, by around $1^{\circ} \mathrm{C}$. As a consequence, the AABW transport evident in Fig. 2a is not clear in Fig. 3a. This is because the observed AABW more closely "overlaps" in $(\theta, \mathrm{S})$ space with the stronger southward transport of NADW, and is obscured. Despite these differences, the overall level of agreement between simulated and observed transports at A5 is encouraging.

Progressing to A3 (Fig. 2b), a northward-flowing warm core of $\sim 21 \mathrm{~Sv}$ is found at lower temperature $\left(22-23^{\circ} \mathrm{C}\right)$ and higher salinity (36.2-36.3 psu), than at A5, due to strong heat loss and evaporation in the Sargasso Sea recirculation gyre. Although the $36^{\circ} \mathrm{N}$ section was not occupied during the study period, the strength and structure of transport is broadly consistent with an earlier 1981 occupation (Roemmich and Wunsch, 1985). Some of the northward transport across A3 at high salinity (above $36 \mathrm{psu}$ ) is due to the additional influence of Mediterranean Water (MW). Exchange at the Straits of Gibraltar (Fig. 2c) is somewhat stronger than observations would suggest. As period-means, the inflow of Atlantic Water is $1.17 \mathrm{~Sv}$ and the outflow of MW is $1.12 \mathrm{~Sv}$. These compare with recent estimates of $0.78 \pm 0.47 \mathrm{~Sv}$ inflow and $0.67 \pm 0.26 \mathrm{~Sv}$ outflow (Tsimplis and Bryden, 2000). The stronger exchange in OCCAM may be related to missing tidal effects, although the estimates based on current meter measurements are also contingent on cross-strait and vertical sampling strategies. The salinity of outflowing MW, in the range 38.0-38.4 psu, is close to observations (see Fig. 6 of Tsimplis and Bryden, 2000).

At A25 (Fig. 2d), the majority of northward transport (17.7 $\mathrm{Sv}$ out of a total of $20.1 \mathrm{~Sv}$ ) is restricted to $6-15^{\circ} \mathrm{C}$, and shifted by as much as 0.8 psu towards lower salinity, relative to northward transports at A3. Compared to observations (Fig. 3b), the southward-flowing NADW in OCCAM is warmer by $\sim 2^{\circ} \mathrm{C}$ and more saline by $\sim 0.2$ psu. These systematic differences in dense water mass properties are likely due to excessive entrainment of surrounding water into overflow waters, a problem that is not unusual in level-coordinate ocean models (Marsh et al., 1996). Property errors are actually somewhat smaller in the present OCCAM experiment, compared to simulations with coupled climate models such as HadCM3 (in which NADW is too saline by $\sim 0.5 \mathrm{psu}$, a longstanding model error, see Wood et al., 1999; Wu et al., 2004).

Transport across AR7W (Fig. 2e) is strikingly cold and fresh, with southward transport of $\sim 15 \mathrm{~Sv}$ in the ranges -2 to $4^{\circ} \mathrm{C}$ and 32.6-35.2 psu. Strong northward and southward fluxes occur in adjacent temperature classes of $4-5^{\circ} \mathrm{C}$ and $3-4^{\circ} \mathrm{C}$, respectively. Strong variability in the formation and transport of LSW limit the long-term representativeness of individual AR7W occupations. However, AR7W has been occupied at least annually since 1990, and from what has been observed (e.g. Pickart et al., 2002), our period-mean transports appear realistic. The temperature and salinity ranges of southward flows are in close agreement with observations at AR7W (e.g. Fig. 8 of Pickart et al., 2002).

By EEL-64N (Fig. 2f), northward transport is almost entirely in the temperature range $6-12^{\circ} \mathrm{C}$ and located on the eastern (EEL) half of the amalgamated section. A large fraction of the cold southward flux is made up of waters derived from overflows through the Denmark Straits (DS) and the Faroe Bank Channel (FBC). Girton et al. (2001) recently estimated the DS overflow, just south of the sill, to be steady at $3.8 \pm 0.8 \mathrm{~Sv}$, while Hansen et al. (2001) observe the FBC overflow gradually decreasing from $\sim 1.9 \mathrm{~Sv}$ in the early 1990's. Added to an extra $\sim 1 \mathrm{~Sv}$ across the ridge between Iceland and the Faroes, the combined $\sim 6.7 \mathrm{~Sv}$ of overflow in recent years is comparable with an earlier estimate 
of 5.6 Sv by Dickson and Brown (1994). South of DS at around $64^{\circ} \mathrm{N}$, and across the $20^{\circ} \mathrm{W}$ part of EEL south of Iceland, Dickson and Brown (1994) estimate that the overflows (denser than $\sigma_{0}=27.8 \mathrm{~kg} \mathrm{~m}^{-3}$ ) have been strengthened by entrainment to $5.1 \mathrm{~Sv}$ and $3.5 \mathrm{~Sv}$, respectively, giving a total of 8.6 Sv. In OCCAM, total southward transport across EEL$64 \mathrm{~N}$ is $14.9 \mathrm{~Sv}$, of which $9.3 \mathrm{~Sv}$ lies in temperature classes below $5^{\circ} \mathrm{C}$ and at potential density above around $27.6 \mathrm{~kg} \mathrm{~m}^{-3}$ (transport at slightly higher temperature/lower density is associated with the East Greenland Current). We therefore conclude that the model overflows across EEL-64N are realistic in strength, although too light by around $0.2 \mathrm{~kg} \mathrm{~m}^{-3}$.

Model Canadian Archipelago (CA) transport of $1.38 \mathrm{~Sv}$ (see Table 2) lies within the estimated range of 0.7-2.5 Sv (Prinsenberg and Bennett, 1987 and Melling, 2000). Compared with recent observations from moorings in one of the three passages of the archipelago (Prinsenberg and Hamilton, 2004), property-binned CA transport (not shown) falls in a temperature range of 0 to $-2^{\circ} \mathrm{C}$, comparable with the observations, and a salinity range of 30.0-32.8 psu, somewhat lower than the observed range of 31.0-33.7 psu.

Figure 4 shows transports partitioned according to potential density, $\sigma_{0}$, in "bins" of width $0.1 \mathrm{~kg} \mathrm{~m}^{-3}$. Fluxes through the Gibraltar Straits are included with fluxes across A3. The sections A25 and AR7W are likewise considered together, as well as A25 separately. The two curves shown in each plot indicate a range of values due to interannual variability over 1985-2002, according to positive and negative excursions from the mean by two standard deviations. The close proximity of upper and lower bounds on transport (with the exception of AR7W) confirm the relative steadiness of transports over 1985-2002. The upper panels show fluxes, the lower panels show cumulative transport, obtained by summing the fluxes from low to high values of $\sigma_{0}$. These fluxes and transports indicate a vigorous thermohaline circulation. The density of northward flows increases with latitude due to air-sea interaction, while the density of southward flows is relatively constant. In fact, the southward flows increase in density between A25-AR7W and A3-GibSt, by just $\sim 0.1 \mathrm{~kg} \mathrm{~m}^{-3}$. This is largely due to gradual southward penetration of overflows which are too light, although entrainment of denser AABW and MW into the NADW layer will also tend to increase the density of that layer (see the reduction in AABW flux, comparing the upper panels of Figs. $4 \mathrm{~b}$ and $4 c)$. The profiles of cumulative transport provide five views of the thermohaline circulation, declining in strength towards the high latitude sinking regions. The non-zero residual values of cumulative transport at high density (see also Table 2) correspond to a long-term barotropic component of the circulation due to Bering Strait throughflow (period-mean value is $\sim 0.8 \mathrm{~Sv}$ ) and the net exchange of freshwater across the ocean surface (in particular, $\sim 0.2 \mathrm{~Sv}$ is gained in the Arctic).

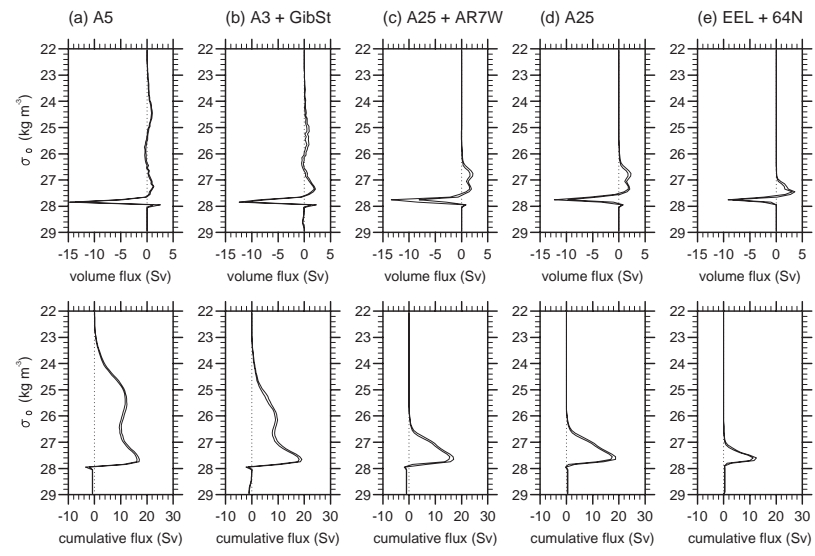

Fig. 4. Model transports partitioned according to potential density, $\sigma_{0}$, in "bins" of width $0.1 \mathrm{~kg} \mathrm{~m}^{-3}$. The upper panels show fluxes. Fluxes through the Gibraltar Straits are included with fluxes across A3. The sections A25 and AR7W are likewise considered together, as well as A25 separately. The lower panels show cumulative transport, obtained by summing the fluxes, from low to high values of $\sigma_{0}$ : (a) $\psi_{\mathrm{A} 5}\left(\sigma_{k}\right)$; (b) $\psi_{\mathrm{A} 3}\left(\sigma_{k}\right)+\psi_{\mathrm{GibSt}}\left(\sigma_{k}\right)$; (c) $\psi_{\mathrm{A} 25}\left(\sigma_{k}\right)+$ $\psi_{\mathrm{AR} 7 \mathrm{~W}}\left(\sigma_{k}\right)$; (d) $\psi_{\mathrm{A} 25}\left(\sigma_{k}\right)$; (e) $\psi_{\mathrm{EEL}}\left(\sigma_{k}\right)+\psi_{64 \mathrm{~N}}\left(\sigma_{k}\right)$. The two curves shown in each plot indicate a range of values due to interannual variability over 1985-2002, according to positive and negative excursions from the period-mean by two standard deviations.

4.2 Net water mass transformation in the four enclosed regions

Figure 5 shows period-mean volume fluxes, cumulative as a function of $\sigma_{0}$, in the four bounded regions. In Fig. 5a, we show differences in "streamfunctions" at the bounding sections shown in Fig. 4 (lower panels), due to the net import of water masses (see Eqs. 5-8). Positive values indicate a diapycnal flux of volume towards higher density. The maximum in this flux increases northwards, from $24.7 \mathrm{~kg} \mathrm{~m}^{-3}$ in the Subtropical Box, to $25.8 \mathrm{~kg} \mathrm{~m}^{-3}$ in the Mid-latitudes Box, to $27.3 \mathrm{~kg} \mathrm{~m}^{-3}$ in the NE Atlantic Box, and $27.7 \mathrm{~kg} \mathrm{~m}^{-3}$ in the Labrador Sea Box.

In Fig. 5b, we show $G_{\text {trend }}\left(\sigma_{0}\right)$, the period-mean trend per region, obtained by summing $\partial_{t} V$ (the term on the left hand side of Eqn. 1), from low to high density:

$$
G_{\text {trend }}\left(\sigma_{0}\right)=-\sum_{\sigma_{k}=20.1}^{\sigma_{k}=\sigma_{0}} \partial_{t} V\left(\sigma_{k}, \sigma_{k-1}\right)
$$

The right hand side of Eqn. (12) is multiplied by -1 as we define positive fluxes towards higher density. $G_{\text {trend }}$ is most conspicuous at high density, reaching $-2 \mathrm{~Sv}$ at $27.8 \mathrm{~kg} \mathrm{~m}^{-3}$. This suggests that the deep water formation rate is too weak by $2 \mathrm{~Sv}$, qualitatively consistent with our earlier finding that deep overflows are too light by $0.2 \mathrm{~kg} \mathrm{~m}^{-3}$. The volume fluxes associated with this trend are negative at most densities, for all four regions. This indicates that the ocean in each region is getting slightly lighter over 1985-2002. The 
(a) net import

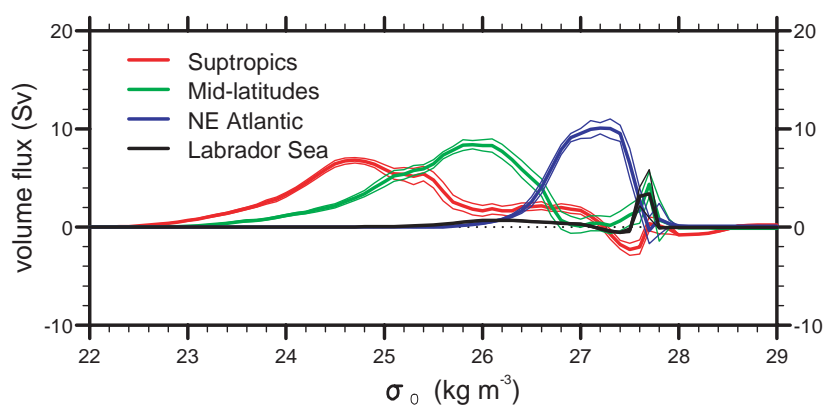

(b) net accumulation

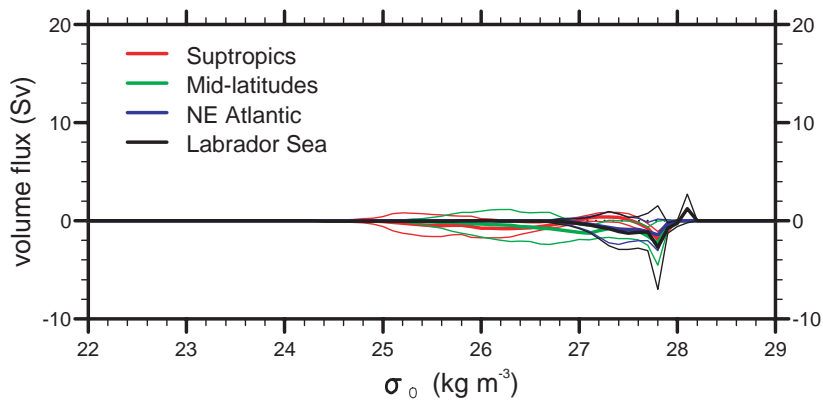

(c) net transformation

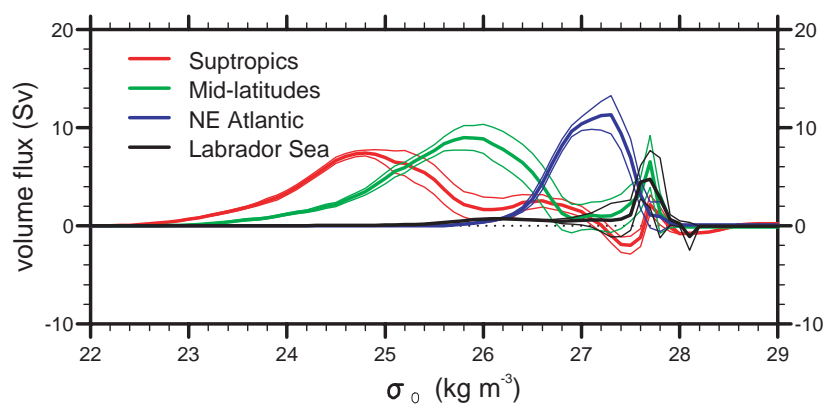

Fig. 5. Period-mean cumulative volume fluxes as a function of $\sigma_{0}$, in the four bounded regions, the Subtropics (red curve), Midlatitudes (green curve), NE Atlantic (blue curve), and Labrador Sea (black curve): (a) $\psi_{\text {net }}^{\text {subtrop }}\left(\sigma_{0}\right), \psi_{\text {net }}^{\text {midlat }}\left(\sigma_{0}\right), \psi_{\text {net }}^{\text {NEAtl }}\left(\sigma_{0}\right)$ and $\psi_{\text {net }}^{\text {LabSea }}\left(\sigma_{0}\right)$, due to net import; (b) $G_{\text {trend }}\left(\sigma_{0}\right)$, due to net accumulation; (c) $G\left(\sigma_{0}\right)$, the net transformation rate, calculated as $\psi_{\text {net }}\left(\sigma_{0}\right)$ $-G_{\text {trend }}\left(\sigma_{0}\right)$ - see Eq. (1). Mean fluxes are indicated by solid lines. Thin lines indicate positive and negative excursions of two standard deviations. Positive fluxes indicate net import in (a), net accumulation in (b), and net transformation towards higher density in (c).

envelope of two standard deviations is relatively wide, due to strong inter-annual variability in water masses, especially in the thermocline range of $25<\sigma_{0}<27.8$, for which the periodmean trend is closer to zero. This suggests that the trend is only partly a model artefact, and may also result from interannual variability in the surface fluxes, especially so in the Labrador Sea.

In Fig. 5c, we show the net water mass transformation rate ( $G$ in Eq. 1), computed by subtracting the volume flux as- sociated with trend from that due to the net import. As the trend is only substantial at high density, net transformation rates are close to net imports - i.e. there is a balance between the transformation and transport of water masses. This net water mass transformation rate is due to the combined effects of surface fluxes and mixing, the former of which we now evaluate.

\subsection{Water mass transformation due to surface fluxes}

We calculate the water mass transformation rates due to surface fluxes, $\left(G_{\text {surf }}\right.$ in Eq. 3). We compare values diagnosed in OCCAM with values diagnosed using two versions of a dataset determined from in situ (ship and buoy) meteorological observations over 1980-1993, the Southampton Oceanography Centre (SOC) flux climatology. We use both the original version of the SOC flux dataset (Josey et al., 1999, referred to as "unadjusted SOC" here), in which there is a global mean ocean heating bias of $30 \mathrm{Wm}^{-2}$, and a subsequent adjusted version in which this bias has been removed using inverse analysis with hydrographic constraints (Grist and Josey, 2003). Note that we have used SOC rather than NCEP as our comparison dataset because fluxes derived from the NCEP meteorological variables have been used to force the model, thus the NCEP fluxes are not independent. Some differences between the values obtained using OCCAM and NCEP fluxes would occur, but only due to differences between sea surface temperatures and sea ice cover in OCCAM, compared with corresponding fields prescribed for the NCEP reanalysis model.

Figure 6 shows surface flux-induced water mass transformation rates $\left(G_{\text {surf }}\right)$ in OCCAM and computed using the SOC heat and freshwater fluxes, for each region. Figure 6a shows the OCCAM average over 1985-2002. The red, green and blue curves in Fig. 6a resemble those in Fig. 5c, as water mass transformation is strongly linked to air-sea exchanges of heat and freshwater. The large difference between the black curves in Fig. 6a and Fig. 5c are attributed to strong mixing (see next section).

We compare surface transformation rates in OCCAM with equivalent rates determined using the SOC fluxes, for the common period of 1985-1993. Figures $6 \mathrm{~b}$ and $6 \mathrm{c}$ show the transformation rate for this period in OCCAM, and using the adjusted SOC fluxes (Grist and Josey, 2003). There is good general agreement in the three Atlantic boxes. Differences between the two sets of curves are summarised as follows:

1. in the Subtropical Box, maximum transformation at lower density (peak $\sim 13 \mathrm{~Sv}$ at $\sigma_{0}=25.6 \mathrm{~kg} \mathrm{~m}^{-3}$ ) in OCCAM, compared with the SOC fluxes (peak $\sim 12 \mathrm{~Sv}$ at $\sigma_{0}=26.0 \mathrm{~kg} \mathrm{~m}^{-3}$ );

2. in the Mid-latitudes Box, maximum transformation at higher density (peak $\sim 12 \mathrm{~Sv}$ at $\sigma_{0}=26.6 \mathrm{~kg} \mathrm{~m}^{-3}$ ) in OCCAM, compared with the SOC fluxes (peak $\sim 13 \mathrm{~Sv}$ at $\sigma_{0}=26.2 \mathrm{~kg} \mathrm{~m}^{-3}$ ); 
3. in the NE Atlantic Box, transformation rates in OCCAM are almost double those obtained with the SOC fluxes, although there is less surface transformation at $\sigma_{0}>27.6 \mathrm{~kg} \mathrm{~m}^{-3}$ in OCCAM, compared with the SOC fluxes.

4. in the Labrador Sea Box, OCCAM, transformation rates peak around $15 \mathrm{~Sv}$ at $\sigma_{0}=27.4 \mathrm{~kg} \mathrm{~m}^{-3}$, and remain high (14 Sv) at $\sigma_{0}=27.6 \mathrm{~kg} \mathrm{~m}^{-3}$, while with the SOC fluxes transformation rates reach only $0.3 \mathrm{~Sv}$.

The large discrepancy between OCCAM and SOC surface transformation rates in the Labrador Sea is clearly associated with differences in surface net heat flux (see below).

Figure $6 \mathrm{~d}$ shows the transformation rate obtained with the unadjusted SOC fluxes. The level of agreement with OCCAM in the three main boxes is now significantly worse than before, which is not surprising given that the unadjusted SOC fluxes are known to significantly underestimate the ocean heat loss to the atmosphere (Josey et al., 1999). However, the transformation rates found using unadjusted SOC fluxes are in better agreement with OCCAM at low density $\left(\sigma_{0}<24.4 \mathrm{~kg} \mathrm{~m}^{-3}\right)$ in the Subtropical and Mid-latitudes Boxes.

To further investigate the differences between Figs. $6 \mathrm{~b}-$ 6d, we examine the 1985-1993 average net surface heat flux. Figure 7 shows the annual mean net heat flux in OCCAM (Fig. 7a), and for adjusted and unadjusted SOC fluxes (Figs. 7b and c). A striking feature in the OCCAM fluxes, is a broad area of strong heat gain, up to $100 \mathrm{Wm}^{-2}$, east of the Grand Banks centered on about $\left(40^{\circ} \mathrm{W}, 48^{\circ} \mathrm{N}\right)$. This feature is absent from the SOC fluxes, and other major datasets that we have investigated including both the NCEP/NCAR and ECMWF reanalyses (not shown). This is largely because the model North Atlantic Current is located about $5^{\circ}$ too far south in longitude range $30-45^{\circ} \mathrm{W}$. This problem is not unusual in level coordinate ocean models (Marsh et al., 1996). Under the surface forcing scheme employed in the model, the unrealistically cold waters in this region are strongly heated by warmer overlying air, primarily through sensible and latent heat exchange, resulting in the abnormal pattern of heat gain.

Significant differences between OCCAM and SOC are found in some other regions but these may be indicative of problems with the SOC fields. The OCCAM heat fluxes reach greater negative extrema over the Gulf Stream, the Irminger Sea, and the Labrador Sea. In particular, we note strong surface cooling in the northwest Labrador Sea which is largely absent in the SOC fluxes. As this region contains very few ship observations it is likely that the SOC heat loss is too weak in the Labrador Sea. The difference between OCCAM and SOC surface fluxes in the Labrador Sea is the major source of disagreement in surface transformation rates. Also apparent in the adjusted climatology is net cooling south of a line stretching roughly from Florida to the Iberian peninsula, in place of the weak heating seen in the (a) OCCAM, 1985-2002

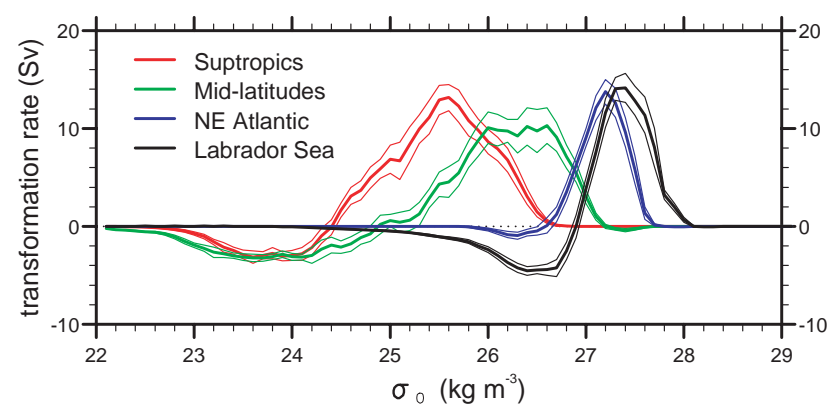

(b) OCCAM, 1985-93

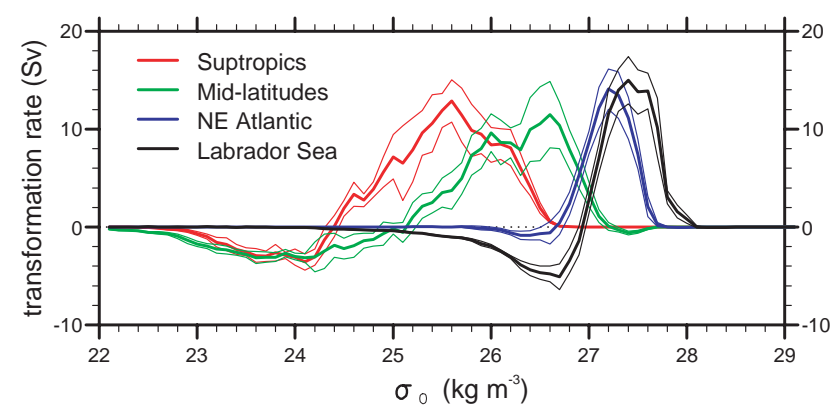

(c) adjusted SOC fluxes, 1985-93

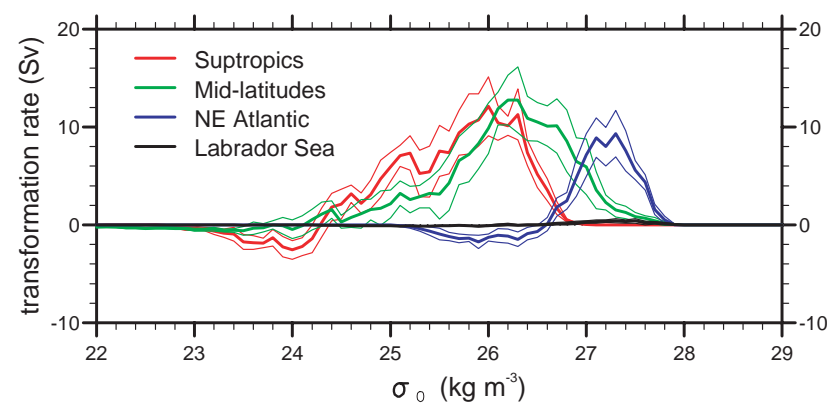

(d) unadjusted SOC fluxes, 1985-93

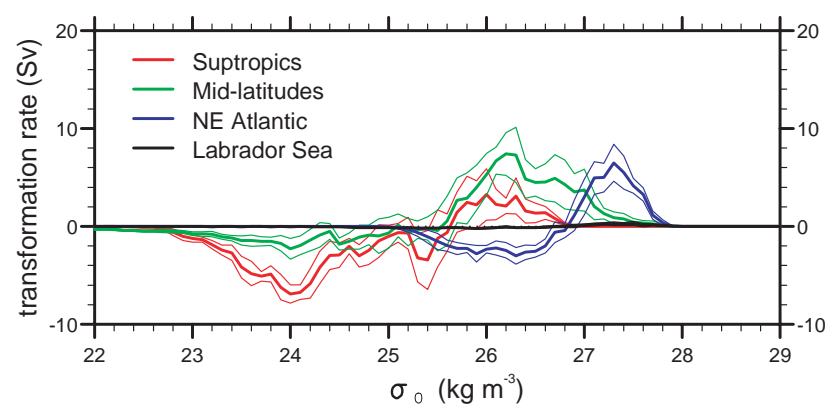

Fig. 6. As Fig. 5, showing surface transformation rates, $G_{\text {surf }}\left(\sigma_{0}\right)$, in the four bounded regions: (a) OCCAM, 1985-2002; (b) OCCAM, 1985-1993; (c) adjusted SOC, 1985-1993; (d) unadjusted SOC, 1985-1993.

OCCAM and the unadjusted fluxes. This is consistent with the findings of Grist and Josey (2003) who note that the unadjusted SOC fluxes are in better agreement (than the adjusted fluxes) with measurements made using research buoys in the 
(a) OCCAM $\min =-274.37 \max =140.46$

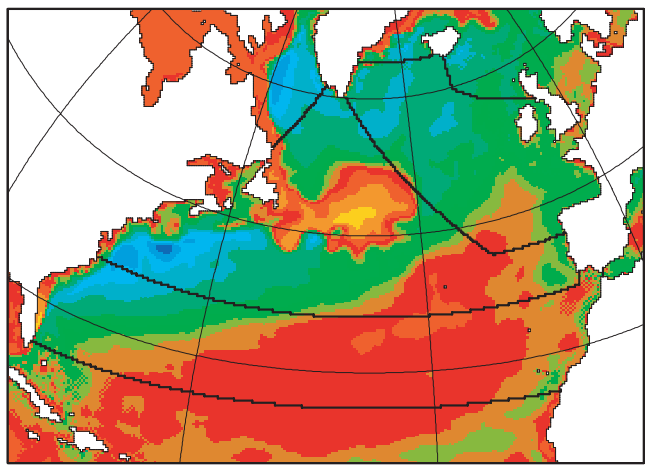

(b) SOC adjusted $\min =-195.33 \max =85.25$

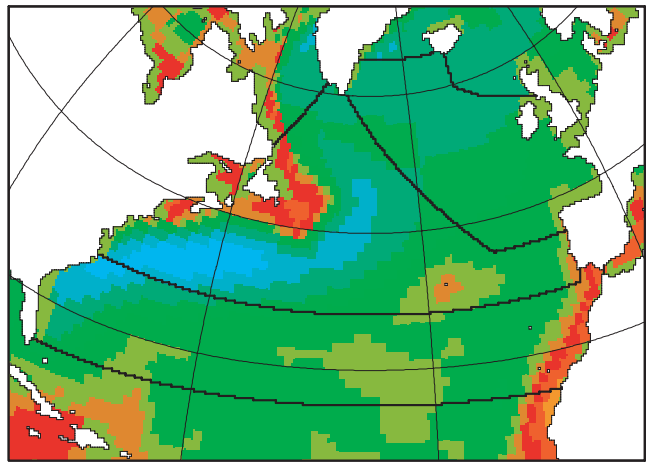

(c) SOC unadjusted $\min =-142.05 \max =116.27$
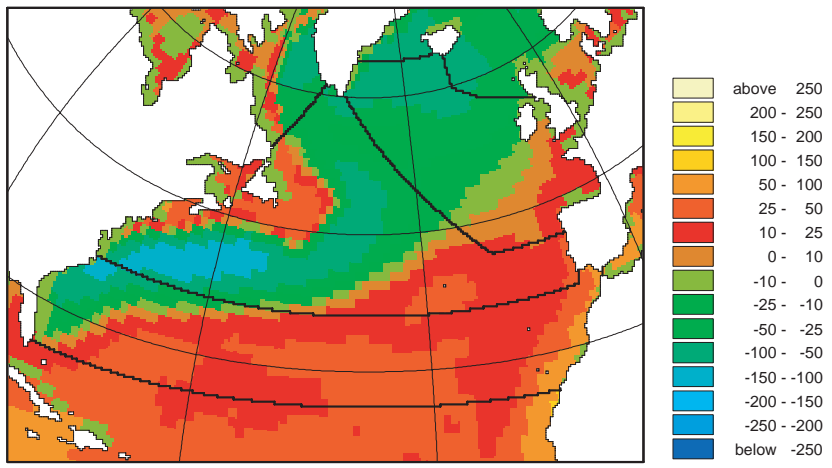

Fig. 7. Net surface heat flux $\left(\mathrm{Wm}^{-2}\right)$ in the North Atlantic, averaged over 1985-1997: (a) OCCAM; (b) SOC adjusted fluxes; (c) SOC unadjusted fluxes. The fluxes are shown on a sub-region of the same rotated grid as in Fig. 1, along with the sections bounding each region.

eastern subtropical gyre. It is therefore encouraging that OCCAM surface transformation rates at low density in the Subtropics Box are closer to transformation rates obtained using the unadjusted SOC fluxes.

More generally, discrepancies between surface transformation rates obtained with OCCAM and SOC fluxes may arise for a variety of reasons:
1. Runoff is neglected in the calculation with SOC fluxes, but is implicitly included in the OCCAM surface freshwater flux. This may explain why transformation rates in the Mid-latitudes Box (strongly influenced by Canadian runoff) are more negative at low density.

2. The monthly-mean OCCAM fluxes include the effects of synoptic time and space scales, whereas these effects are probably under-sampled in the SOC fluxes. This may explain generally higher and "sharper" maxima in the OCCAM transformation rates, associated with narrow boundary currents and eddies.

3. The globally-adjusted SOC fluxes still contain regional biases as discussed by Grist and Josey (2003).

4. The atmospheric data and bulk formulae used in the surface forcing of OCCAM also introduce biases to the OCCAM fluxes, relative to the SOC fluxes.

Detailed investigation of the above issues is beyond the scope of the present paper. Our main conclusion is that the OCCAM values are consistent with those expected on the basis of our current understanding of the surface flux fields, as represented by the SOC flux climatology.

We now consider OCCAM surface formation rates, $M_{\text {surf }}$, in each region over 1985-2002. Figure 8 shows Hovmuller plots of annual surface flux-driven formation rate in each $\sigma_{0}$ interval over ranges corresponding to strongest consumption and formation of water masses in each region. The dashed upright lines define the $\sigma_{0}$-range for each of the four water masses defined in the Introduction. In the Subtropics, surface formation takes place above about $\sigma_{0}=25.6 \mathrm{~kg} \mathrm{~m}^{-3}$ (Fig. 8a). Formation rates in the $\sigma_{0}$-range of EDW are relatively weak and intermittent, with less water being formed in the latter part of the period considered (1995-2002). In the Mid-latitudes (Fig. 8b), the surface consumption and formation of water mass has shifted by $\sim 0.5 \mathrm{~kg} \mathrm{~m}^{-3}$, and substantial formation rates are now found in the $\sigma_{0}$-range of STMW. In the NE Atlantic Box (Fig. 8c), water mass consumption and formation is more coherent than in the two other regions, being well defined in the ranges $26.6<\sigma_{0}<27.2 \mathrm{~kg} \mathrm{~m}^{-3}$, and the $\sigma_{0}$-range of SPMW, respectively. A similarly coherent picture emerges for the Labrador Sea (Fig. 8d), with consumption over $26.7<\sigma_{0}<27.4 \mathrm{~kg} \mathrm{~m}^{-3}$ and formation over the $\sigma_{0}$-range of LSW. Also evident in Fig. $8 \mathrm{~d}$ is a decadal transient in surface formation of LSW, with formation rates in the "dense LSW" range $27.8<\sigma_{0}<27.9 \mathrm{~kg} \mathrm{~m}^{-3}$ notably exceeding $4 \mathrm{~Sv}$ in 1990. Aside from the effects of surface fluxes, water masses are modified by mixing, which is the process we consider next.

\subsection{Water mass transformation due to mixing}

We obtain transformation rates due to "total" mixing, $G_{\text {mix }}$, as the difference between net and surface forced 
(a) Subtropics

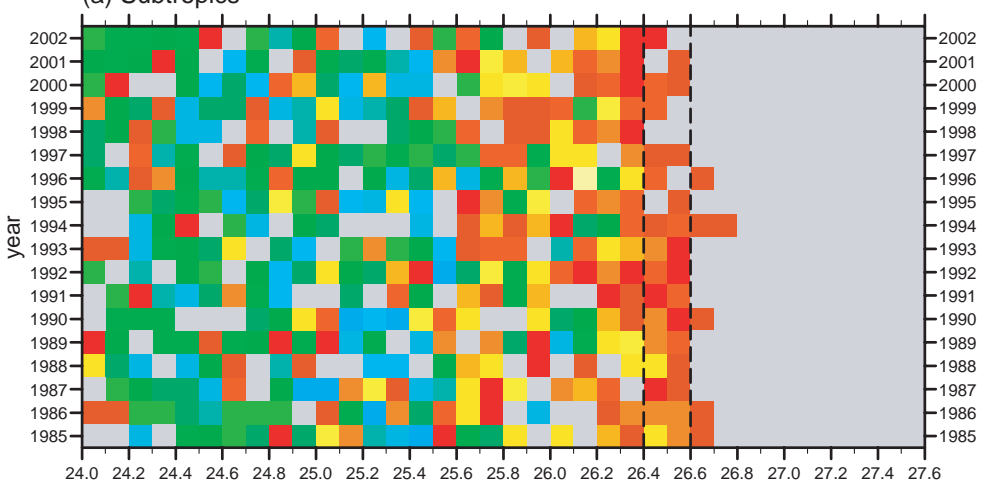

(b) Mid-latitudes

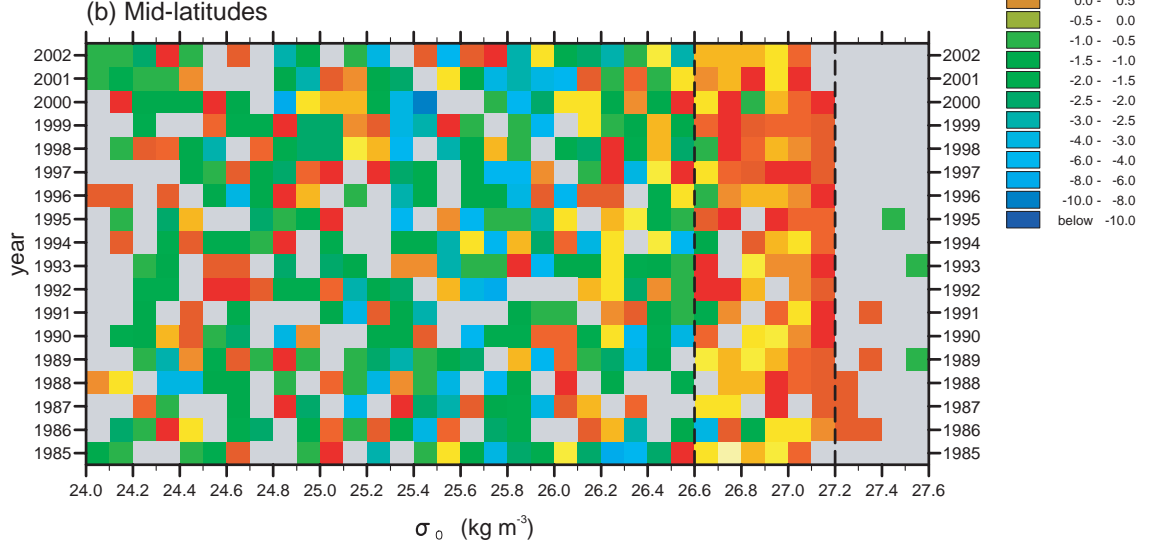

(c) NE Atlantic

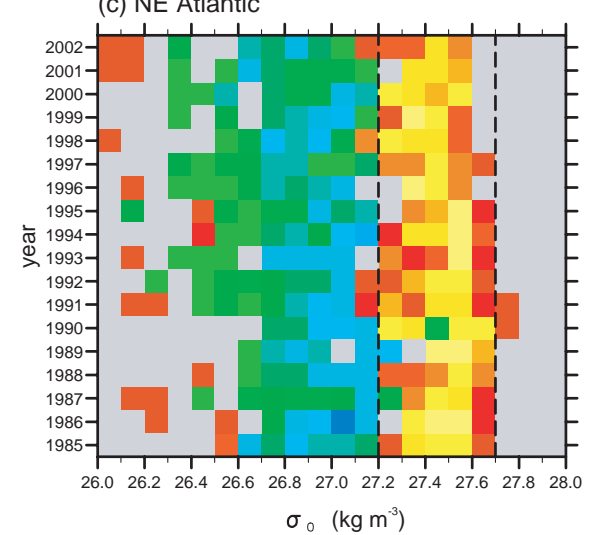

(d) Labrador Sea

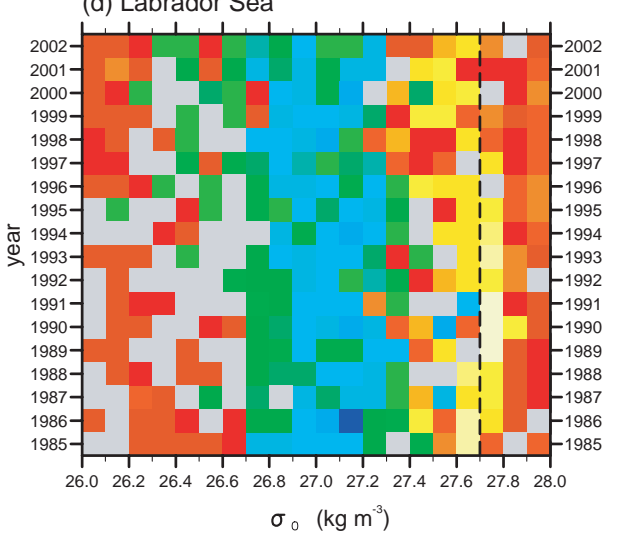

Fig. 8. Hovmuller plots of surface formation rate, $M_{\text {surf }}$, in each $\sigma_{0}$-interval over limited ranges corresponding to formation of selected water masses: (a) EDW in the Subtropics Box; (b) STMW in the Mid-latitudes Box; (c) SPMW in the NE Atlantic Box; (d) LSW in the Labrador Sea. Formation rates in the range -0.5 to $0.5 \mathrm{~Sv}$ are grey-shaded. The dashed upright lines define the $\sigma_{0}$-range for each of the four water masses.

transformation rates, for each region - see Fig. 9. In the Subtropics Box (Fig. 9a), $G_{\text {mix }}$ is alternately positive and negative, as one would expect of diapycnal mixing, acting to transform light and dense waters towards intermediate density over three density ranges: $22.0<\sigma_{0}<26.4 \mathrm{~kg} \mathrm{~m}^{-3}$; $26.4<\sigma_{0}<27.7 \mathrm{~kg} \mathrm{~m}^{-3} ; 27.7<\sigma_{0}<28.6 \mathrm{~kg} \mathrm{~m}^{-3}$. This characteristic diapycnal mixing suggests that the spurious mixing is not a serious problem in the model. In the Mid-latitudes
Box (Fig. 9b), the residual mixing curve appears more positive than negative, implying overall density gain. This is possibly a consequence of cabbeling through isopycnal mixing, either across the strong near-surface fronts in the region, or between warm, saline Mediterranean Water and surrounding cooler, fresher waters at intermediate depths. We cannot, however, rule out limitations in our methodology. Possible reasons for this positive bias are outlined in the Discussion. 
(a) Subtropics

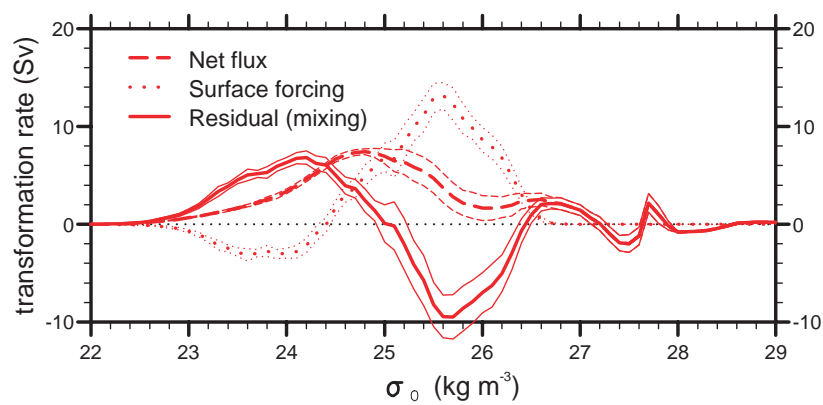

(b) Mid-latitudes

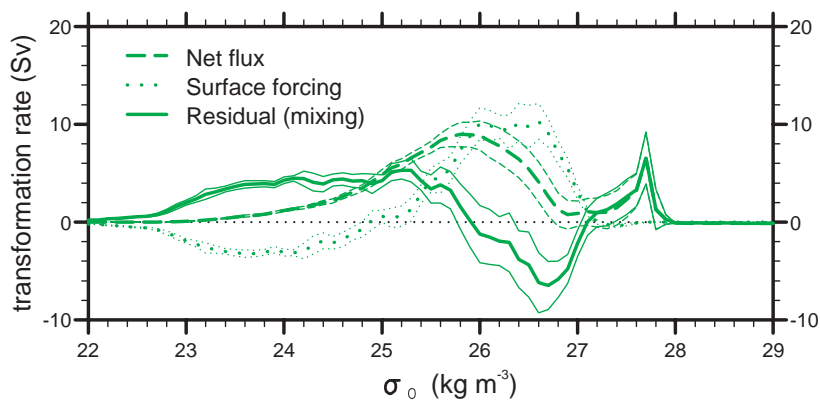

(c) NE Atlantic

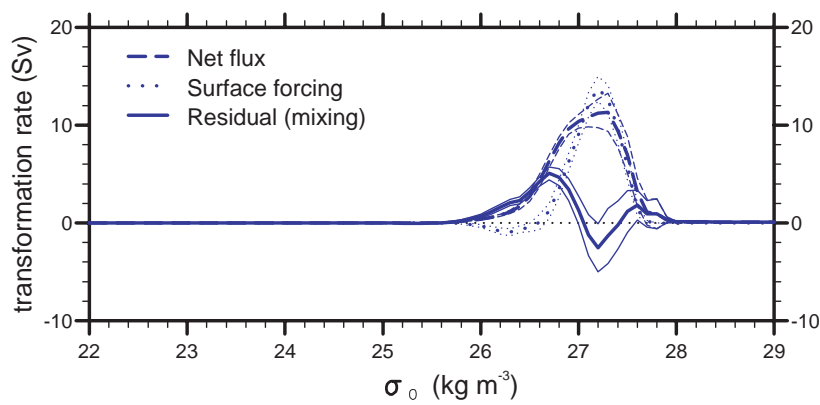

(d) Labrador Sea

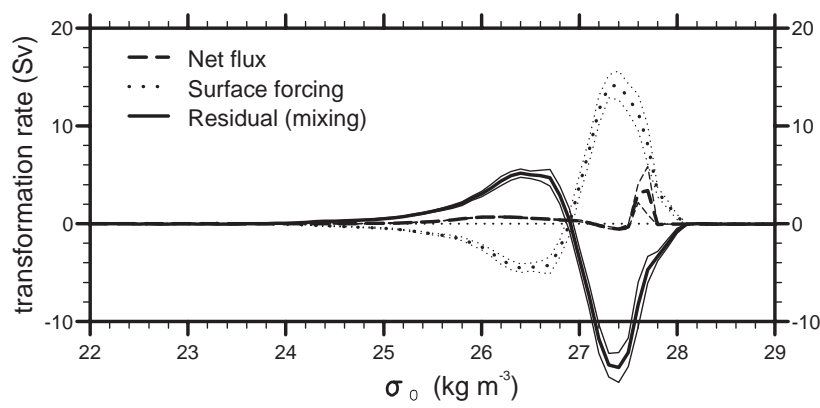

Fig. 9. As Fig. 5, showing transformation rates due to mixing, $G_{\text {mix }}\left(\sigma_{0}\right)$ (solid curves), obtained as a residual term between net transformation rates, $G\left(\sigma_{0}\right)$ (dashed curves), and surface forced transformation rates, $G_{\text {surf }}\left(\sigma_{0}\right)$ (dotted curves): (a) Subtropics; (b) Mid-latitudes; (c) NE Atlantic; (d) Labrador Sea.

Despite this positive offset, mixing in the Mid-latitudes Box acts to transform light and dense waters to intermediate den- sity in the broad range $22.0<\sigma_{0}<27.1 \mathrm{~kg} \mathrm{~m}^{-3}$. In the NE Atlantic Box (Fig. 9c), we again see that mixing has a net positive effect, but we also find an overall transformation to intermediate density in the range $25.7<\sigma_{0}<27.4 \mathrm{~kg} \mathrm{~m}^{-3}$. In the Labrador Sea Box (Fig. 9d), there is a strong transformation over the range $25.0<\sigma_{0}<28.0 \mathrm{~kg} \mathrm{~m}^{-3}$, towards an intermediate density of around $27 \mathrm{~kg} \mathrm{~m}^{-3}$.

We now consider the annual formation rates due to mixing, $M_{\text {mix }}$. Figure 10 shows Hovmuller plots of these formation rates over 1985-2002, across a wide range of density. The formation and consumption of water in different density classes, due to mixing, is now clear. The density ranges of the principal water masses are again indicated by two dashed upright lines in Fig. 10a-d. In the Subtropics Box (Fig. 10a), there is a broad swathe of formation in the intermediate density range $24.2<\sigma_{0}<25.6 \mathrm{~kg} \mathrm{~m}^{-3}$. This formation is at the expense of lighter water and denser water. The denser water is strongly consumed in the range $25.6<\sigma_{0}<26.6 \mathrm{~kg} \mathrm{~m}^{-3}$, which includes EDW. At higher density, mixing leads to weaker formation in the density class $26.7<\sigma_{0}<27.5 \mathrm{~kg} \mathrm{~m}^{-3}$. At high density the alternate "bands" of strong formation and consumption reveal vigorous mixing of NADW, AABW and MW in the density range $27.6<\sigma_{0}<28.8 \mathrm{~kg} \mathrm{~m}^{-3}$. Similar swathes of formation and consumption are clear in the Mid-latitudes Box (Fig. 10b), the NE Atlantic Box (Fig. 10c) and the Labrador Sea Box (Fig. 10d), with strong consumption rates in density ranges corresponding to STMW, SPMW and LSW, respectively. Mixing of LSW during 1990-1993 is rather exceptional, leading paradoxically to the formation of LSW in a density range $27.7<\sigma_{0}<27.8 \mathrm{~kg} \mathrm{~m}^{-3}$, at rates of $2-4 \mathrm{~Sv}$.

\subsection{Water mass formation rates over 1985-2002}

Time series of the annual surface-driven, mixing-driven and net formation rates for each water mass are shown in Figure 11a-d and these reveal considerable variability within the period considered. In particular, the LSW surface formation rate strengthens and weakens over 1985-1995, attaining a peak of around $16 \mathrm{~Sv}$ in 1990. This transient episode is well established from repeated hydrographic surveys of the Labrador Sea (Dickson et al., 1996). Also revealed in Fig. 11 is strong interannual-to-decadal variability in the surface formation of STMW and SPMW. EDW surface formation is relatively weak and declines over much of the period.

The mixing-driven formation rates shown in Fig. 11 (thin solid curves) are generally negative, indicating consumption of each water mass within the region of formation. Furthermore, variability in the consumption rates largely matches that seen in the surface-driven formation rates (dotted curves) in the case of EDW and STMW. This suggests that much of the EDW and STMW formed through surface heat and freshwater exchange is consumed in the same year and region. If this consumption is largely due to entrainment of water into the mixed layer, then the variability is likely linked (as is 


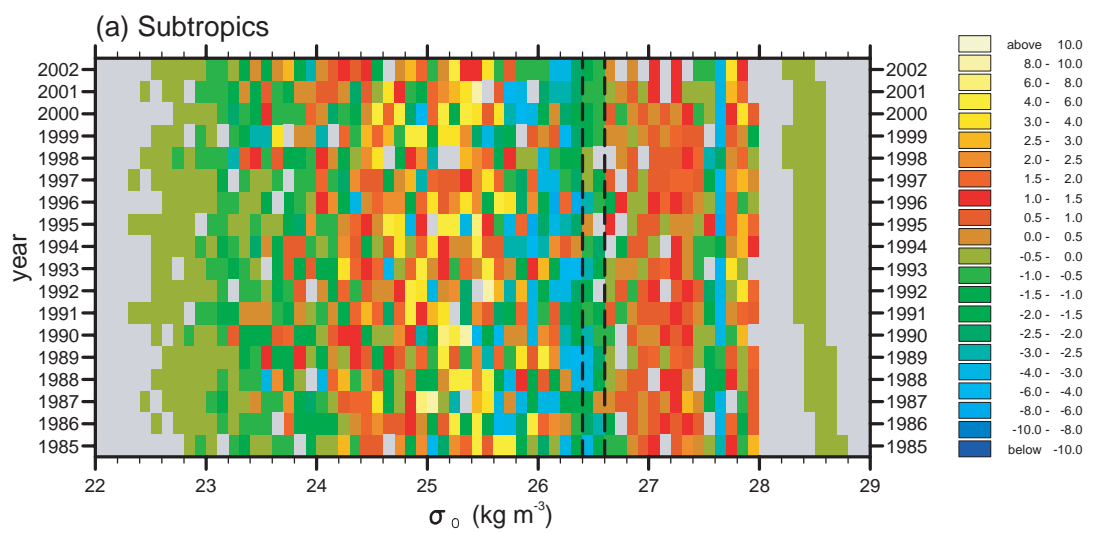

(b) Mid-latitudes

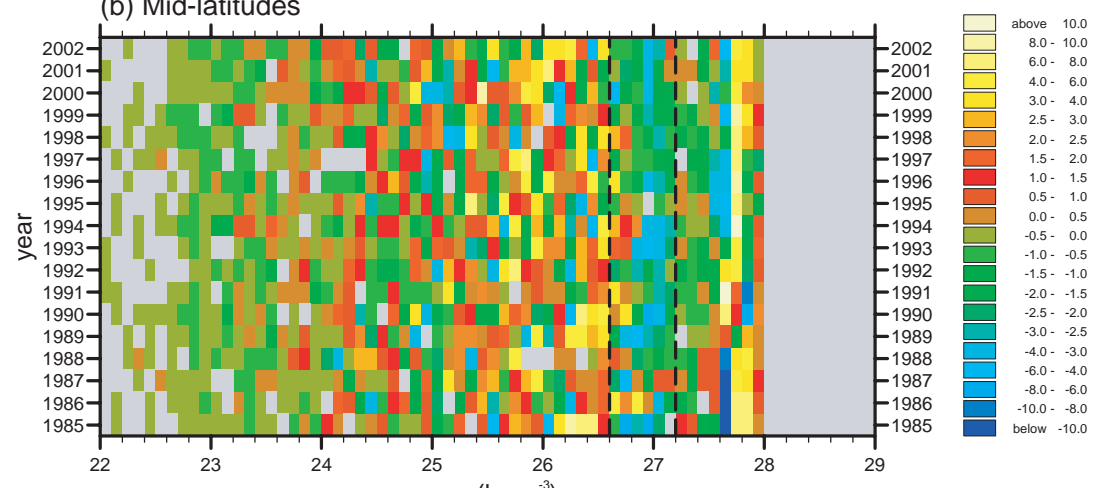

(c) NE Atlantic
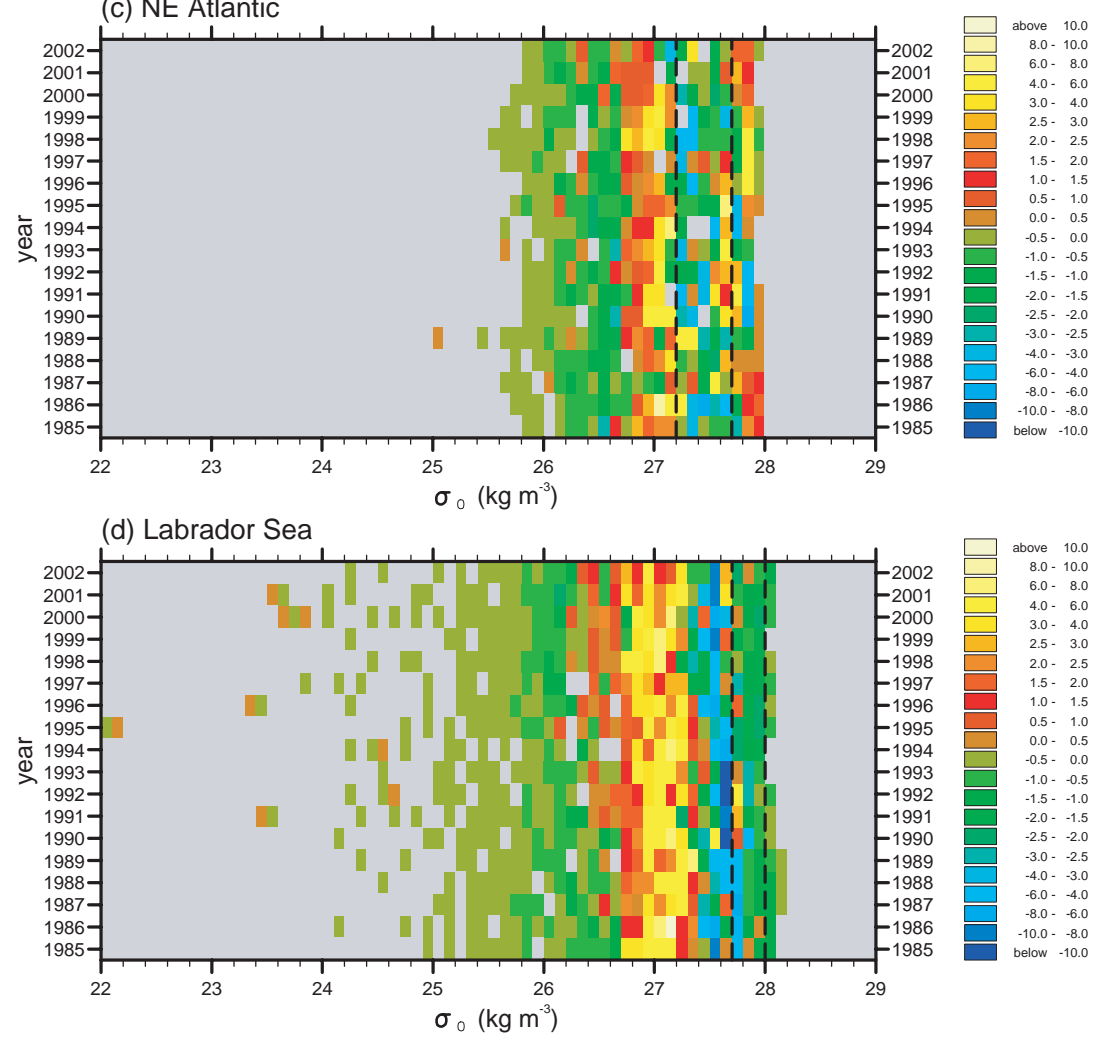

Fig. 10. Hovmuller plots of formation rates due to mixing, $M_{\text {mix }}$ (as Fig. 7): (a) Subtropics; (b) Mid-latitudes; (c) NE Atlantic; (d) Labrador Sea. Formation rates in the range -0.1 to $0.1 \mathrm{~Sv}$ are grey-shaded. The dashed upright lines define the $\sigma_{0}$-range for each of the four water masses. 
(a) EDW (Subtropics)

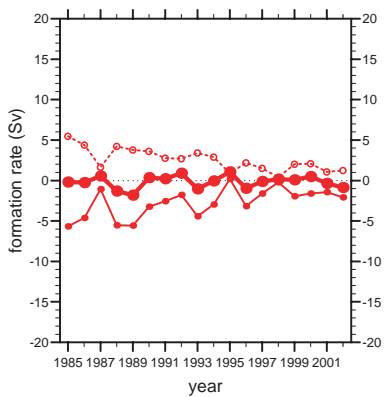

(c) SPMW (NE Atlantic)

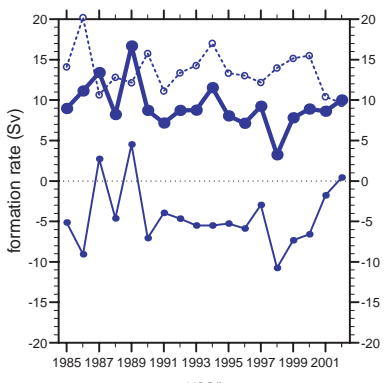

year (b) STMW (Mid-latitudes)

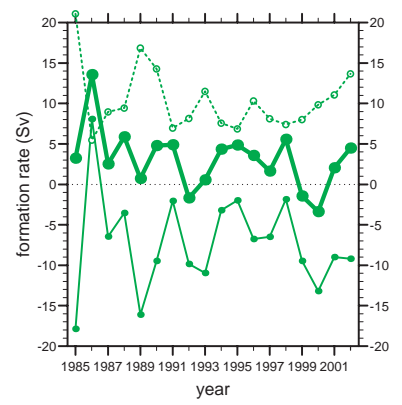

(d) LSW (Labrador Sea)

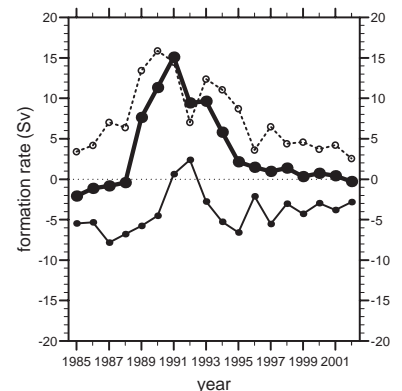

year

Fig. 11. Time series of water mass formation rates: (a) EDW in the Subtropics Box; (b) STMW in the Mid-latitudes Box; (c) SPMW in the NE Atlantic Box; (d) LSW in the Labrador Sea. Dotted curves show formation rates due to surface fluxes. Thin solid curves show formation rates due to mixing. Thick solid curves show net formation rates. These water mass formation rates are obtained by summing $M_{\text {surf }}, M_{\text {mix }}$ and $M_{\text {net }}$ over the $\sigma_{0}$-range for each water mass.

variability in formation rates) to large inter-annual fluctuations in winter mixed layer depth. In the case of SPMW, mixing-driven formation rates are considerably weaker than surface formation rates, resulting in a net formation rate of around $10 \mathrm{~Sv}$. A similar situation is found in the case of the LSW transient. The implication is that SPMW and LSW are consumed by mixing outside their respective formation regions. Indeed, Fig. 10 indicates some consumption of SPMW and LSW elsewhere, in the Mid-latitudes Box in most years (Fig. 10b), and in the NE Atlantic Box in 19901992 and 1994-1995 (Fig. 10c), respectively.

\section{Summary and discussion}

We have diagnosed North Atlantic water mass transformation in an eddy-permitting ocean simulation forced by observed fluxes for the period 1985-2002. We selected four basin-wide sections which have been occupied in recent years and are central to ongoing efforts to monitor the thermohaline circulation. Along with short sections across gateways (the Gibraltar Straits, the Canadian Archipelago), these

sections bound four regions: the Subtropics, Mid-latitudes, the Northeast Atlantic and the Labrador Sea. The regions broadly represent the formation sites of Eighteen Degree Water, Subtropical Mode Water, Subpolar Mode Water and Labrador Sea Water. Partitioning diapycnal fluxes in potential density, a water mass budget is obtained for each region and year. Terms in the budget comprise surfaceforced transformation rates, boundary exchanges and unsteadiness. Property-binned transports across the bounding sections compare favourably with available observations and the thermohaline circulation is realistically vigorous. We find a small degree of unsteadiness at high density, probably related to excessive mixing in the overflows between the Fram Strait and Cape Farewell. Overall, there is a good balance between the formation, transport and consumption of water masses throughout the simulation. The most notable Atlantic variability during 1985-2002, associated with the episode of strong renewal of Labrador Sea Water during 1989-1994 (Dickson et al., 1996), is well simulated.

For a common period 1985-1993, model surface transformation rates are compared with equivalent rates computed using the adjusted SOC climatology (Grist and Josey, 2003) - globally-balanced fluxes of heat and freshwater which are derived from ship observations. There is an overall reasonable agreement between the two sets of transformation rates. However, compared to surface transformation rates computed from the flux dataset, those in the model reach more extreme maxima in the subtropics, the northeast Atlantic and the Labrador Sea. This is consistent with more extreme heat loss in these regions of OCCAM. Most crucial in the context of water mass transformation at LSW densities, strong heat loss in the northwest Labador Sea of OCCAM is largely absent in the SOC fluxes. This feature of the OCCAM simulation is consistent with a similar pattern of surface net heat flux obtained with NCEP reanalysis data (Pickart et al., 2002). The weak heat loss in the Labrador Sea in the SOC climatology is unsurprising given that very few ship observations are available for this region (see Fig. 2 of Josey et al., 1999).

The peak LSW surface formation rate of $\sim 16 \mathrm{~Sv}$ in OCCAM well exceeds a $\sim 6 \mathrm{~Sv}$ peak rate obtained from NCEP reanalysis data for a larger region $\left(40-70^{\circ} \mathrm{W}, 50-65^{\circ} \mathrm{N}\right)$ and averaged over 1958-1999 (Khatiwala et al., 2002). LSW formation in the early 1990's was, however, higher than the long-term average. Rhein et al. (2002) use an inventory of chlorofluorocarbon to estimate a formation rate of LSW over 1988-1994 of at least $8.1-10.8 \mathrm{~Sv}$. Based on these observed estimates, we consider that the OCCAM peak rate of $15 \mathrm{~Sv}$ may be too large by about $50 \%$. Compared with satellite data, winter sea surface temperatures in OCCAM are biased high by $2-4^{\circ} \mathrm{C}$ in the Labrador Sea (manscript in prep.), which would enhance surface heat loss during cold air outbreaks and further increase early 1990's LSW formation.

We further note that transformation rates obtained with the adjusted SOC fluxes are generally shifted towards higher 
density. This is particularly the case in the subtropics, and may be associated with "over-adjustment" of the SOC fluxes in this region. This is most evident in the eastern subtropical gyre, where net surface cooling in the adjusted SOC fluxes is inconsistent with research buoy measurements of net warming (Grist and Josey, 2003). However, we also note incorrect positioning of the North Atlantic Current (NAC) in OCCAM, which is located too far south to the east of the Grand Banks. This leads to unrealistic surface heating (up to $100 \mathrm{Wm}^{-2}$ ) of cold surface waters advected into the region by the Labrador Current. Incorrect positioning of the NAC in OCCAM is likely due to excessive dissipation at $1 / 4^{\circ}$ resolution (viscosities are given in Table 1). In models similar to OCCAM, a realistic NAC path in the "Northwest Corner" is obtained at resolutions of $1 / 10^{\circ}$ and $1 / 12^{\circ}$ (Treguier et al., 2005). Only at such a high resolution can dissipation be reduced to levels sufficiently low for strong vertical penetration of eddy kinetic energy and a stronger topographic influence on the NAC as it encounters the tail of the Grand Banks and the Newfoundland seamounts (Bryan et al., 2005 ${ }^{1}$ ).

Few other model studies of the recent circulation and water mass transformation in the North Atlantic have been undertaken. Gulev et al. (2003) report a longer simulation than ours, using an Atlantic sector implementation of the SPEM ocean model at resolution of $\sim 1.2^{\circ}$, spanning 1958-1997. While their simulation spans more decadal variability, notably the effects of a low-to-high transition of the NAOindex, the mean state is rather unrealistic due to weak overturning and heat transport. Using the OPA model, Beismann and Barnier (2004) obtain an overturning circulation more realistic in mean strength and variability, through improved representation of dense overflows. Hall et al. (2004) find that much of the interannual variation of Gulf Stream heat transport in a $\sim 1 / 6^{\circ}$ version of CLIPPER, forced with winds and fluxes over 1979-1999, is due to the Ekman response to changes in wind forcing but that the NAO has no significant effect on heat transports. The present study complements an earlier study of the thermohaline circulation in the same OCCAM simulation (Marsh et al., 2005). Together, these studies provide a new overview of recent changes in the North Atlantic.

The most uncertain component in water mass transformation, both observationally and in models, is diapycnal mixing. The mixing transformation rate curves in OCCAM are broadly similar to those obtained in previous model studies (e.g. Nurser et al., 1999). We can also compare our results with recent inverse estimates of interior diapycnal volume transports by Lumpkin and Speer (2003), henceforth LS, who considered "Subtropical", "Subpolar" and "Overflow" boxes of the North Atlantic. The Subtropical box of

\footnotetext{
${ }^{1}$ Bryan, F. O., Hecht, M. W., and Smith, R. D.: Resolution convergence and sensitivity studies with North Atlantic circulation models, Part I: The Western Boundary Current System, Ocean Modelling, submitted, 2005.
}

LS shares the same southern boundary (A5) as our Subtropics box but extends further north to fully incorporate the subtropical gyre. The "Subpolar" box of LS includes a northern portion of our Mid-latitudes Box, and all of the Labrador Sea. The Overflow box of LS includes broadly the northern half of our NE Atlantic box.

Comparisons are clearest for surface and thermocline waters in the subtropics. In their Subtropical box, LS estimate diapycnal transports (positive towards decreasing neutral density) which vary from a minimum of $-7.5 \pm 1.5 \mathrm{~Sv}$ in their "Surface" layer $\left(\sigma_{0}<26.0 \mathrm{~kg} \mathrm{~m}^{-3}\right)$ to a maximum of $7.5 \pm 3.5 \mathrm{~Sv}$ in their "Thermocline" layer $\left(26.0<\sigma_{0}<27.1 \mathrm{~kg} \mathrm{~m}^{-3}\right)$. Noting our opposite sign convention, these extremes compare well to OCCAM "Subtropics" box values of $7 \pm 1 \mathrm{~Sv}\left(\right.$ at $\sigma_{0}=24.2 \mathrm{~kg} \mathrm{~m}^{-3}$ ) and $-10 \pm 2 \mathrm{~Sv}$ (at $\sigma_{0}=25.6 \mathrm{~kg} \mathrm{~m}^{-3}$ ) - see Fig. 10a. The implied mixing-driven formation rates are $\sim 15 \mathrm{~Sv}$ in $\mathrm{LS}\left(24.7<\sigma_{0}<26.4 \mathrm{~kg} \mathrm{~m}^{-3}\right)$ and $\sim 17 \mathrm{~Sv}$ in OCCAM $\left(24.2<\sigma_{0}<25.6 \mathrm{~kg} \mathrm{~m}^{-3}\right)$.

In their Subpolar box, LS estimate three distinct maxima and minima in diapycnal transport, with notably a maximum of $2 \pm 1 \mathrm{~Sv}$ at $\sigma_{0}=27.1 \mathrm{~kg} \mathrm{~m}^{-3}$ and a minimum of around $-2 \pm 1 \mathrm{~Sv}$ at a lower limit for the density of LSW. This is in broad agreement with mixing transformation rates in the Mid-latitudes Box of OCCAM, where we diagnose $0 \pm 1.5 \mathrm{~Sv}$ at around $\sigma_{0}=27.1 \mathrm{~kg} \mathrm{~m}^{-3}$ and a maximum of around $6 \pm 3 \mathrm{~Sv}$ at $\sigma_{0}=27.7 \mathrm{~kg} \mathrm{~m}^{-3}$. Given the divergence of diapycnal transports across these density ranges, both LS and OCCAM suggest that mixing consumes SPMW at mid-latitudes: at $\sim 4 \mathrm{~Sv}$ in LS and at $\sim 6 \mathrm{~Sv}$ in the OCCAM Mid-latitudes Box.

The Overflow box of LS is dominated by maximum and minimum diapycnal transport in the density ranges for bottom waters and upper deep waters, respectively. Mixing transformation rates in the NE Atlantic Box of OCCAM are considerably different from those in the Overflow Box of LS. In particular, the diapycnal transport estimates of LS imply $\sim 7 \mathrm{~Sv}$ formation of "Lower Deep" waters through mixing of "Upper Deep" and "Bottom" waters in the Overflow Box. This mixing process is not captured in our diagnosis of OCCAM, possibly because model overflows are too light as a result of spurious mixing further upstream.

Mixing rates at high density in OCCAM may also be inaccurate due to our "offline" method of diagnosis. "Online" computation of diapycnal fluxes and water mass transformation is a challenging prospect, and has only been attempted once before to our knowledge (Nurser et al., 1999). Only by this method is it possible to partition mixing between different processes. Using our indirect method, and over the large regions we have chosen, it is not possible to identify specific mixing processes. Projecting hydrographic observations onto three-dimensional geostrophic streamlines, PérezBrunius et al. (2004) find two distinct processes driving the transformation of warm waters traversing the subpolar gyre: cross-frontal mixing of cold, fresh subpolar waters and salty, warm Gulf Stream waters in the west; surface cooling, convective mixing and entrainment of salty thermocline waters 
in the east. In an isopycnic model of the Atlantic, Nurser et al. (1999) find substantial water mass transformation in the vicinity of boundary currents around the subpolar gyre, due to lateral diapycnal mixing in the mixed layer. Now that we have established vigorous water mass transformation across the subpolar gyre of OCCAM, we plan to investigate these separate mixing processes through more detailed diagnosis of future simulations.

To conclude, we have shown using the OCCAM eddy pemitting model that there is considerable interannual-todecadal variability in the formation and consumption rates of the following key water masses: EDW, STMW, SPMW and LSW. In the subtropics, anomalies in EDW and STMW formation rates are largely offset by similar anomalies in consumption rate, in the same year. Coincidence of strong formation and consumption rates in a given year is probably due to the link between surface density flux and winter mixed layer deepening at the regional scale, and does not negate the possibility of an oceanic "memory" of anomalous surface fluxes in preceding years. Haines and Old (2005) find that surface-formed STMW anomalies are re-entrained into the mixed layer after typically 5 years. To the extent that STMW is formed and consumed in the same region, we cannot identify when water masses formed in a given year are consumed. In the subpolar gyre, however, there is less correspondance between anomalies in surface-driven formation and mixing-driven consumption. This may reflect clearer geographical separation of formation and consumption sites, or a weaker physical link between processes of formation and consumption, in the subpolar gyre, compared to the subtropical gyre.

Acknowledgements. This work was supported by the "Large Scale Long Term Ocean Circulation" and "Ocean Variability and Climate" Core Strategic Programmes of the UK Natural Environment Research Council. The A5 and A25 datasets were kindly provided by $\mathrm{H}$. Bryden and M. Álvarez. The final version of the manuscript owed much to the insightful and constructive comments of two anonymous reviewers.

Edited by: B. Barnier

\section{References}

Alfultis, M. A. and Cornillon, P.: Annual and interannual changes in the North Atlantic STMW layer properties, J. Phys. Oceanogr., 31, 2066-2086, 2001.

Álvarez, M., Bryden, H. L., Pérez, F. F., Ríos, A. F., and Rosón, G.: Physical and biogeochemical fluxes and net budgets in the Subpolar and Temperate North Atlantic, J. Mar. Res., 60, 191226, 2002.

Beismann, J.-O. and Barnier, B.: Variability of the meridional overturning circulation of the North Atlantic: sensitivity to overflows of dense water masses, Ocean Dynamics, 54, 92-106, 2004.
Bishop, J. K. B. and Rossow, W. B.: Spatial and temporal variability of global surface solar irradiance, J. Geophys. Res., 96, $16839-$ 16858, 1991.

Bryan, K.: A numerical method for the study of the circulation of the world ocean, J. Comput. Phys., 4, 347-376, 1969.

Coward, A. C. and de Cuevas, B. A.: The OCCAM 66 Level Model: physics, initial conditions and external forcing, SOC Internal Report No. 99, 2005.

Cox, M. D.: A primitive equation 2-dimensional model of the ocean. GFDL Ocean Group Technical Report No. 1. Geophysical Fluid Dynamics Laboratory/NOAA, Princeton University, Princeton, H.J. 08542, USA, 143 pp., 1984.

Danabasoglu, G. and McWilliams, J. C.: Sensitivity of the global ocean circulation to parameterizations of mesoscale tracer transports, J. Climate, 8, 2967-2987, 1995.

Dickson, R. R. and Brown, J.: The production of North Atlantic Deep Water: Sources, rates and pathways, J. Geophys. Res., 99, 12 319-12 341, 1994.

Dickson, R. R., Lazier, J., Meincke, J., Rhines, P., and Swift, J.: Long-term coordinated changes in the convective activity of the North Atlantic, Prog. Oceanogr., 38, 241-295, 1996.

Dickson, R. R., Curry, R., and Yashayaev, I.: Recent changes in the North Atlantic, Phil. Trans. R. Soc. Lond. A, 361, 1917-1934, 2003.

Ganachaud, A.: Large-scale mass transports, water mass formation, and diffusivities estimated from World Ocean Circulation Experiment (WOCE) hydrographic data, J. Geophys. Res., 108, C7, 3213, doi:10.1029/2002JC001565, 2003.

Garrett, C., Speer, K., and Tragou, E.: The relationship between water mass formation and the surface buoyancy flux, with application to Phillips' Red Sea model, J. Phys. Oceanogr., 25, 16961705, 1995.

Girton, J. B., Sanford, T. B., and Käse, R. H.: Synoptic sections of the Denmark Strait Overflow, Geophys. Res. Lett., 28, 1619$1622,2001$.

Gent, P. R. and McWilliams, J. C.: Isopycnal mixing in ocean circulation models, J. Phys. Oceanogr., 20, 150-155, 1990.

Gouretski, V. V. and Jancke, K.: A new World Ocean climatology: Optimal interpolation of historical and WOCE hydrographic data on neutral surfaces, WOCE Rep. 162/98 (Available from WOCE Special Analysis Centre, Max-Planck-Institute, Hamburg, Germany), 1998.

Griffies, S. M.: The Gent-McWilliams skew flux, J. Phys. Oceanogr., 28, 831-841, 1998.

Griffies, S. M., Gnanadesikan, A., Pacanowski, R. C., Larichev, V. D., Dukowicz, J. K., and Smith, R. D.: Isoneutral diffusion in a Z-coordinate ocean model, J. Phys. Oceanogr., 28, 805-830, 1998.

Griffies, S. M., Pacanowski, R. C., and Hallberg, R. W.: Spurious diapycnal mixing associated with advection in a $z$-coordinate ocean model, Mon. Wea. Rev., 128, 538-564, 2000.

Grist, J. P. and Josey, S. A.: Inverse analysis adjustment of the SOC air-sea flux climatology using ocean heat transport constraints, J. Climate, 20, 3274-3295, 2003.

Gulev, S. K., Barnier, B., Knochel, H., and Molines, J.-M.: Water Mass Transformation in the North Atlantic and Its Impact on the Meridional Circulation: Insights from an Ocean Model Forced by NCEP-NCAR Reanalysis Surface Fluxes, J. Climate, 16, 3085-3110, 2003. 
Haines, K. and Old, C.: Diagnosing Natural Variability of North Atlantic Water Masses in HadCM3, J. Climate, 18, 1925-1941, 2005.

Hall, N. M. J., Barnier, B., Penduff, T., and Molines, J. M.: Interannual variation of Gulf Stream heat transport in a high-resolution model forced by reanalysis data, Clim. Dyn., 23, 341-351, 2004.

Hansen, B., Turrell, W. R., and Østerhus, S.: Decreasing overflow from the Nordic seas into the Atlantic Ocean through the Faroe Bank channel since 1950, Nature, 411, 927-930, 2001.

Hazeleger, W. and Drijfhout, S. S.: Eddy subduction in a model of the subtropical gyre, J. Phys. Oceanogr., 30, 677-695, 2000.

Hirschi, J., Baehr, J., Marotzke, J., Stark, J., Cunningham, S., and Beismann, J.-O.: A monitoring design for the Atlantic meridional overturning circulation, Geophys. Res. Lett., 30, 1413, doi:10.1029/2002GL016776, 2003.

Hunke, E. C. and Dukowicz, J. K.: An elastic-viscous-plastic model for sea ice dynamics, J. Phys. Oceanogr., 27, 1849-1867, 1997.

Josey, S. A., Kent, E. C., and Taylor, P. K.: New insights into the ocean heat budget closure problem from analysis of the SOC airsea flux climatology, J. Climate, 12, 2856-2880, 1999.

Kalnay, E., Kanamitsu, M., Kistler, R., Collins, W., Deaven, D., Gandin, L., Iredell, M., Saha, S., White, G., Woollen, J., Zhu, Y., Chelliah, M., Ebisuzaki, W., Higgins, W., Janowiak, J., Mo, K.C., Ropelewskia, C., Leetmaa, A., Reynolds, R., and Jenne, R.: The NCEP/NCAR reanalysis project, Bull. Amer. Meteor. Soc., 77, 437-495, 1996.

Khatiwala, S., Schlosser, P., and Visbeck, M.: Rates and mechanisms of water mass transformation in the Labrador Sea as inferred from tracer observations, J. Phys. Oceanogr., 32, 666-686, 2002.

Kwon, Y.-O. and Riser, S. C.: North Atlantic Subtropical Mode Water: A history of ocean-atmosphere interaction 1961-2000, Geophys. Res. Lett., 31, L19307, doi:10.1029/2004GL021116, 2004.

Large, W.G. McWilliams, J. C., and Doney, S. C.: Oceanic vertical mixing: a review and a model with a non-local boundary layer parameterization, Rev. Geophys., 32, 363-403, 1994.

Large, W. G., Danabasoglu, G., and Doney, S. C.: Sensitivity to Surface Forcing and Boundary Layer Mixing in a Global Ocean Model: Annual-Mean Climatology, J. Phys. Oceanogr., 27, 2418-2446, 1997.

Lavín, A. M., Bryden, H. L., and Parrilla, G.: Mechanisms of heat, freshwater, oxygen and nutrient transports and budgets at $24.5^{\circ} \mathrm{N}$ in the subtropical North Atlantic, Deep-Sea Res., 50, 1099-1128, 2003.

Lumpkin, R. and Speer, K.: Large-scale vertical and horizontal circulation in the North Atlantic Ocean, J. Phys. Oceanogr., 33, 1902-1920, 2003.

Marsh, R., Roberts, M. J., New, A. L., and Wood, R. A.: An intercomparison of a Bryan-Cox-type ocean model and an isopycnic ocean model. Part II: The subtropical gyre and meridional heat transport, J. Phys. Oceanogr., 26, 1528-1551, 1996.

Marsh, R., de Cuevas, B. A., Coward, A. C., Bryden, H. L., and Álvarez, M.: Thermohaline circulation at three key sections in the North Atlantic over 1985-2002, Geophys. Res. Lett., 32, L10604, doi:10.1029/2004GL022281, 2005.

Marshall, J. C., Nurser, A. J. G., and Williams, R. G.: Inferring the subduction rate and period over the North Atlantic, J. Phys. Oceanogr., 23, 1315-1329, 1993.
Marshall, J., Jamous, D., and Nilsson, J.: Reconciling thermodynamics and dynamic methods of computation of water-mass transformation rates, Deep-Sea Res. I, 46, 545-572, 1999.

McCartney, M. S. and Talley, L. D.: Warm-to-cold conversion in the northern North Atlantic Ocean, J. Phys. Oceanogr., 14, 922-935, 1984.

McDougall, T. J.: Parameterizing mixing in inverse models, in: Dynamics of Oceanic Internal Gravity Waves, edited by: Müller, P. and Henderson, D., Proc. Sixth. Aha Huliko'a Hawaiian Winter Workshop, University of Hawaii at Manoa, 355-386, 1991.

Melling, H.: Exchanges of freshwater through the shallow straits of the North American Arctic, in: Freshwater Budget of the Arctic Ocean, edited by: Lewis, E. L., NATO/WCRP/AOSB, Kluwer Acad. Publ., Boston, 479-502, 2000.

Niiler, P. P. and Stevenson, J.: The heat budget of tropical ocean warm-water pools, J. Mar. Res., 40 (Suppl.), 465-480, 1982.

Nurser, A. J. G. and Marsh, R.: Water mass transformation theory and the meridional overturning streamfunction, International WOCE Newsletter, 31, 36-39, 1998.

Nurser, A. J. G., Marsh, R., and Williams, R. G.: Diagnosing water mass formation from air-sea fluxes and surface mixing, J. Phys. Oceanogr., 29, 1468-1487, 1999.

Pérez-Brunius, P., Rossby, T., and Watts, D. R.: Transformation of the warm waters of the North Atlantic from a geostrophic streamfunction perspective, J. Phys. Oceanogr., 34, 2238-2256, 2004.

Pickart, R. S., Torres, D. J., and Clarke, R. A.: Hydrography of the Labrador Sea during Active Convection, J. Phys. Oceanogr., 32, 428-457, 2002.

Prinsenberg, S. J. and Bennett, E. B.: Mixing and transports in Barrow Strait, the central part of the Northwest Passage, Cont. Shelf Res., 7, 913-935, 1987.

Prinsenberg, S. J. and Hamilton, J.: The oceanic fluxes through Lancaster Sound of the Canadian Arctic Archipelago, ASOF Newsletter, 2, 8-11, 2004.

Rhein, M., Fischer, J., Smethie, W. M., Smythe-Wright, D., Weiss, R. F., Mertens, C., Min, D.-H., Fleischmann, U., and Putzka, A.: Labrador Sea Water: pathways, CFC-inventory and formation rates, J. Phys. Oceanogr., 32, 648-665, 2002.

Roemmich, D. and Wunsch, C.: Two transatlantic sections: meridional circulation and heat flux in the subtropical North Atlantic Ocean, Deep-Sea Res., 32, 619-664, 1985.

Rossow, W. B. and Schiffer, R. A.: ISCCP Cloud Data Products, Bull. Amer. Meteor. Soc., 72, 2-20, 1991.

Semtner, A. J.: A general circulation model for the World Ocean. Technical Report No. 9, Dept. Meteorology, University of California, Los Angeles, 99 pp., 1974.

Semtner, A. J.: A model for the thermodynamic growth of sea ice in numerical investigations of climate, J. Phys. Oceanogr., 6, 379389, 1976.

Speer, K. and Tziperman, E.: Rates of water mass formation in the North Atlantic Ocean, J. Phys. Oceanogr., 22, 93-104, 1992.

Speer, K.: A note on average cross-isopycnal mixing in the North Atlantic Ocean, Deep Sea Res., 44, 1981-1990, 1997.

Spencer, R. W.: Global oceanic precipitation from the MSU during 1979-1991 and comparisons to other climatologies, J. Climate, 6, 1301-1326, 1993.

Steele, M., Morley, R., and Ermold, W.: A global ocean hydrography with a high quality Arctic Ocean, J. Climate, 14, 2079-2087, 2001. 
Thierry, V., Mercier, H., Grit, C., Gaillard, F., and Autret, E.: Seasonal and interannual variability of the Subpolar Mode Waters in the North Atlantic. Abstract of poster presented at CLIVAR Workshop on "North Atlantic Thermohaline Circulation variability”, Kiel, Germany, 13-16 September 2004 (see http: //www.ifm.uni-kiel.de/allgemein/naw2004.htm), 2004.

Treguier, A. M., Theetten, S., Chassignet, E. P., Penduff, T., Smith, R., Talley, L., Beismann, J. O., and Böning, C.: The North Atlantic subpolar gyre in four high-resolution models, J. Phys. Oceanogr., 35, 757-774, 2005.

Tsimplis, M. S. and Bryden, H. L.: Estimation of the transports through the Strait of Gibraltar, Deep-Sea Res. I, 47, 2219-2242, 2000.

Tziperman, E.: On the role of interior mixing and air-sea fluxes in determining the stratification and circulation of the oceans, J. Phys. Oceanogr., 16, 680-693, 1986.
Valdivieso da Costa, M., Mercier, H., and Tréguier, A. M.: Effects of the mixed layer time variability on kinematic subduction rate diagnostics, J. Phys. Oceanogr., 35, 427-443, 2005.

Walin, G.: On the relation between sea-surface heat flow and thermal circulation in the ocean, Tellus, 34, 187-195, 1982.

Wood, R. A., Keen, A. B., Mitchell, J. F. B., and Gregory, J. M.: Changing spatial structure of the thermohaline circulation in response to atmospheric $\mathrm{CO}_{2}$ forcing in a climate model, Nature, 399, 572-575, 1999.

Wu. P., Wood, R. A., and Stott, P.: Does the recent freshening trend in the North Atlantic indicate a weakening thermohaline circulation?, Geophys. Res. Lett., 31, L02301, doi:10.1029/2003GL018584, 2004.

Xie, P., and Arkin, P. A.: Analyses of global monthly precipitation using gauge observations, satellite estimates, and numerical model predictions, J. Climate, 9, 840-858, 1996. 